JANAINA PATRICIO DE LIMA

\title{
Potencial evocado auditivo de tronco encefálico em gerbils submetidos à isquemia e sepse
}

Dissertação apresentada à Faculdade de Medicina da Universidade de São Paulo para obtenção do título de Mestre em Ciências

Programa de: Ciências da Reabilitação Área de Concentração: Comunicação Humana Orientadora: Profa. Dra. Eliane Schochat

São Paulo 
Dados Internacionais de Catalogação na Publicação (CIP)

Preparada pela Biblioteca da

Faculdade de Medicina da Universidade de São Paulo

Creprodução autorizada pelo autor

Lima, Janaina Patrício de

Potencial evocado auditivo de tronco encefálico em gerbils submetidos à isquemia e sepse / Janaina Patricio de Lima. -- São Paulo, 2012.

Dissertação(mestrado)--Faculdade de Medicina da Universidade de São Paulo.

Programa de Ciências da Reabilitação. Área de concentração: Comunicação Humana.

Orientadora: Eliane Schochat.

Descritores: 1.Potenciais auditivos evocados 2.Potenciais auditivos evocados do tronco encefálico 3.Sepse 4.Isquemia 5.Anestesia 6.Ketamina

USP/FM/DBD-117/12 
Dedicatória 
Aos meus pais, com todo amor. 
Agradecimentos 


\section{AGRADECIMENTOS}

À Deus, por tudo que tenho;

Aos meus pais por todo o amor, dedicação e incentivo;

À minha orientadora, Professora Doutora Eliane Schochat, exemplo de profissional e de ser humano. Obrigada pelo apoio, confiança, oportunidade e amizade;

Ao Professor Doutor Irineu Tadeu Velasco, pela oportunidade e espaço para a realização desse trabalho;

À equipe do LIM-51, em especial as biólogas Suely K.K. Ariga e Denise F. Barbeiro e ao Doutor Francisco Soriano, pelo auxílio na realização desse estudo, pela atenção que sempre demonstraram por mim;

Às Professoras Doutoras Renata Mamede, Carla Gentile e Ivone Ferreira Neves por todas as contribuições no exame de qualificação;

Ao Professor Doutor Luiz Roberto Giorgetti de Britto pela atenção e disponibilidade em me ajudar quando precisei; 
À equipe de audiologistas do LIF em Processamento Auditivo pelo apoio, modelo e amizade. Em especial à Fonoaudióloga Caroline Nunes Rocha por todas as estatísticas realizadas;

Ao Professor Luiz Roberto Braz, pela correção da língua portuguesa à qual esse estudo foi submetido;

Aos meus amigos por estarem sempre por perto;

E aos meus familiares por torcerem por mim mesmo que à distância.

Muito obrigada! 
"Há um tempo em que é preciso abandonar as roupas usadas, que já tem a forma do nosso corpo, e esquecer os nossos caminhos, que nos levam sempre aos mesmos lugares. É o tempo da travessia: e, se não ousarmos fazê-la, teremos ficado, para sempre, à margem de nós

mesmos."

(Fernando Pessoa) 


\section{NORMATIZAÇÃO ADOTADA}

Esta dissertação está de acordo com as seguintes normas, em vigor no momento desta publicação:

Referências: adaptado de International Committee of Medical Journals Editors (Vancouver)

Universidade de São Paulo. Faculdade de Medicina. Serviço de Biblioteca e Documentação. Guia de apresentação de dissertações, teses e monografias. Elaborado por Anneliese Carneiro da Cunha, Maria Julia de A.L. Freddi, Maria F. Crestana, Marinalva de Souza Aragão, Suely Campos Cardoso, Valéria Vilhena. $2^{\mathrm{a}}$ ed. - São Paulo: Serviço de Biblioteca e Documentação SBD/FMUSP, 2005.

Abreviatura dos títulos dos periódicos de acordo com List of Journals Indexed in Index Medicus. 


\section{Sumário}

Lista de Abreviatura, símbolos e siglas

Lista de Figuras

Lista de Quadros

Lista de Gráficos

Lista de Tabelas

Resumo/Summary

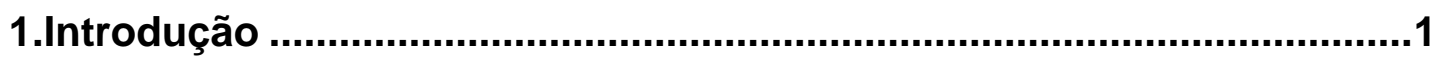

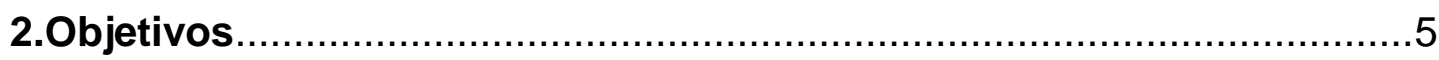

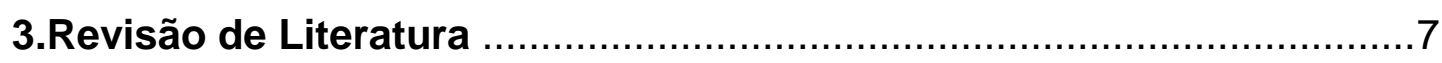

3.1.Acidente Vascular Cerebral Isquêmico....................................8

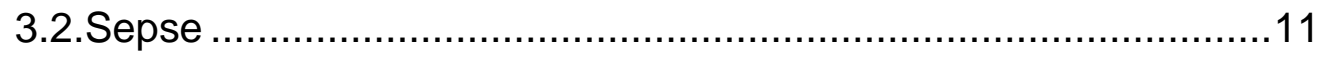

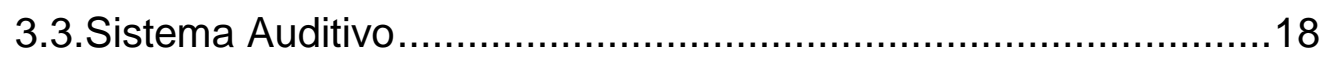

3.4.Potencial Evocado Auditivo ...........................................20

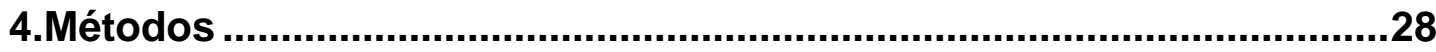

4.1.Modelo Experimental.................................................29

4.2.Procedimentos de isquemia e sepse .......................................30

4.3.Avaliação Eletrofisiológica ..............................................32

4.4.Extração de RNA e PCR em tempo real ..................................35

4.5.Método Estatístico .....................................................38 


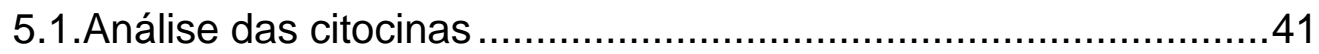

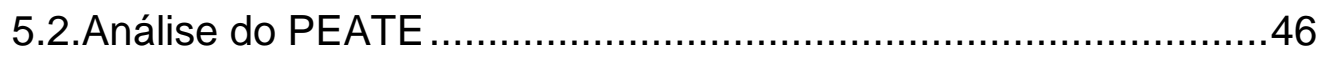

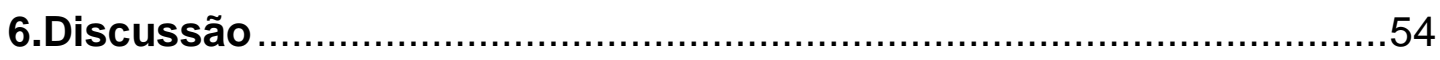

6.1.Análise de citocinas dos sangues dos animais ..........................55

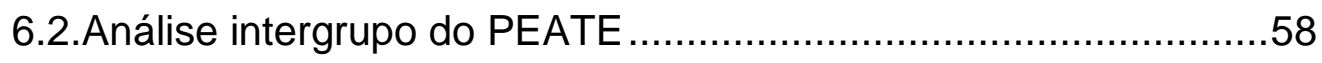

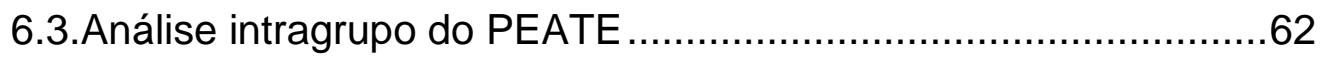

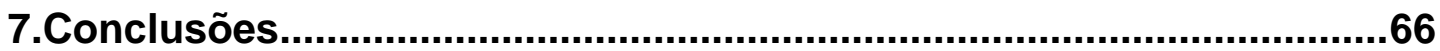

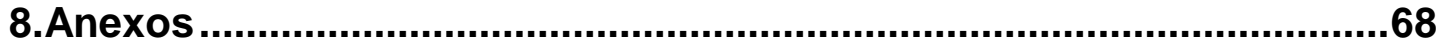

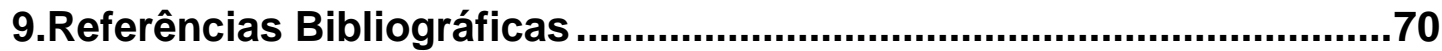




\section{Lista de Abreviatura}

\begin{tabular}{ll} 
AA & Ácido Aracdônico \\
AC & Anticorpo \\
AVC & Acidente Vascular Cerebral \\
Ca $^{2+}$ & Cálcio \\
CAMP & Adenosina Monofosfato Cíclico \\
CGM & Corpo geniculado medial \\
Cl & Colículo inferior \\
COS & Complexo olivar superior \\
GABA & Gamma-AminoButyric Acid \\
IL & Interleucina \\
K & Potássio \\
LL & Lemnisco lateral \\
LPS & Lipopolissacarídeo \\
Na & Sódio \\
NC & Núcleo coclear \\
NF-kB & Fator de transcrição Kappa B \\
NMDA & N-metil-D-aspartato \\
NO & Óxido Nítrico \\
PAF & Fator de Ativação Plaquetária \\
PAMPS & Padrões Moleculares Associados a Patógenos \\
PCR & Polymerase Chain Reaction \\
PEA & Potencial Evocado Auditivo \\
& \\
\hline
\end{tabular}


PEATE Potencial Evocado Auditivo de Tronco Encefálico

RNA Ácido ribonucléico

SIRS Síndrome da Resposta Inflamatória Sistêmica

SNC Sistema Nervoso Central

TLR Toll-like receptor

TNF $\alpha \quad$ Fator de Necrose Tumoral Alfa

UTI Unidade de Terapia Intensiva 


\section{Símbolos e Siglas}

\begin{tabular}{|c|c|}
\hline $\mathrm{dB}$ & decibel \\
\hline $\mathrm{ms}$ & milissegundos \\
\hline $\mathrm{mmHg}$ & milímetro de mercúrio \\
\hline${ }^{\circ} \mathrm{C}^{+}$ & graus Celsius \\
\hline bpm & batimentos por minuto \\
\hline ipm & incursões por minuto \\
\hline $\mathrm{L}$ & litro \\
\hline$\alpha$ & alfa \\
\hline $\mathrm{Hz}$ & Hertz \\
\hline et al. & e outros \\
\hline $\mathrm{N}$ & número de animais \\
\hline g & gramas \\
\hline $\mathrm{mg}$ & miligrama \\
\hline $\mathrm{Kg}$ & kilograma \\
\hline$\mu l$ & microlitro \\
\hline $\mathrm{nm}$ & manômetro \\
\hline $\mathrm{K} \Omega$ & K Ohm \\
\hline$\mu \mathrm{s}$ & microssegundos \\
\hline $\mathrm{ml}$ & mililitro \\
\hline$<$ & menor \\
\hline
\end{tabular}




\section{Lista de Figuras}

Figura 1- Modelo de invasão microbiana na sepse ................................16

Figura 2- Procedimento de isquemia realizado no gerbil ........................31

Figura 3- Captação do potencial evocado auditivo ...............................33

Figura 4- Registro das coletas do PEATE.....................................34

Figura 5- Traçado da média do PEATE em cada grupo estudo em todos os momentos de coleta (pré, A, C, D e E) ...........................................49 


\section{Lista de Quadros}

Quadro 1- Sequência de primers para a RCP 


\section{Lista de Gráficos}

Gráfico 1- Nível da citocina IL-6 nos diferentes grupos estudados 42

Gráfico 2- Nível da citocina TNF-a nos diferentes grupos estudados .43

Gráfico 3- Nível da citocina IL-10 nos diferentes grupos estudados .45

Gráfico 4- Média da latência da onda V do PEATE nas diferentes situações

de estudo dos grupos: Controle (A), Isquemia (B), Sepse (C), Sham (D), Isquemia e Sepse (E) e Sham e Sepse (F) 


\section{Lista de Tabelas}

Tabela 1- Valores da citocina IL-6 entre os grupos estudados .42

Tabela 2- Valores da citocina TNF- $\alpha$ entre os grupos estudados .44

Tabela 3- Valores da citocina IL-10 entre os grupos estudados .45

Tabela 4- Média e desvio padrão (DP) das latências da onda V do PEATE por grupo em todos os momentos do estudo, e $\mathrm{N}$ correspondente .47

Tabela 5- Comparação intergrupos das médias das latências das ondas V do PEATE nas diferentes situações do estudo .51

Tabela 6- Comparação intragrupos das médias das latências das ondas V do PEATE nas diferentes situações de coleta .53 


\section{RESUMO}

LIMA JP. Potencial Evocado Auditivo de Tronco Encefálico em gerbils submetidos à isquemia e sepse [dissertação]. São Paulo: Faculdade de Medicina, Universidade de São Paulo; 2012.

Introdução: O Acidente Vascular Cerebral do tipo isquêmico é um quadro clínico que afeta milhares de pessoas no mundo. Como resultado dessa injúria observamos morte neuronal, e no decorrer natural de recuperação, o indivíduo pode desenvolver a sepse. A sepse é uma resposta inflamatória sistêmica que pode levar o indivíduo a morte. No seu desenvolvimento há a produção de diversas citocinas que caracterizam o processo inflamatório no organismo. Para avaliar as condições clínicas de um paciente com esse quadro o Potencial Evocado Auditivo de Tronco Encefálico (PEATE) pode ser útil,uma vez que ele não é um procedimento invasivo, sua técnica é rápida e pode ser feita à beira do leito. Porém, por outro lado, o PEATE pode ser sensível ao uso de alguns anestésicos. Objetivos: Fazer análise das citocinas IL-6, IL-10 e TNF- $\alpha$ no decorrer da sepse; verificar os valores de latência do PEATE em gerbils submetidos à isquemia e sepse; e verificar a influência do anestésico ketamina associado à xilazina nos valores do PEATE desses animais. Método: Foram coletados os PEATEs de 72 gerbils machos adultos que foram divididos em 6 grupos, a saber: controle, sepse, isquemia, sham, isquemia com sepse e sham com sepse. Para a indução de sepse foi aplicado Lipopolissacarídeo (LPS) intraperitoneal nos gerbils. Os animais foram anestesiados antes das coletas com ketamina associada à xilazina, seus PEATEs foram coletados antes de qualquer procedimento (coleta base), após isquemia e 2, 4, 8 e 24 horas após a aplicação de LPS. Foi avaliada a latência absoluta da onda V, e os valores foram comparados intra e intergrupos. As citocinas IL-6, IL-10 e TNF- $\alpha$ foram analisadas e comparadas em cada grupo estudado. Resultados: Foi observado aumento das citocinas IL-6, IL-10 e TNF- $\alpha$ no decorrer da sepse. Houve diferença estatisticamente significante nos grupos submetidos à sepse no valor da latência da onda $V$ em relação aos demais grupos. Observou-se, também, aumento da latência da onda $V$ após a aplicação sucessiva do anestésico ketamina/xilazina em todos os grupos estudados. Conclusão: Houve aumento dos níveis das citocinas IL-6, IL-10 e TNF- $\alpha$ nos animais que sofreram aplicação de LPS, revelando uma alteração de expressão gênica de moléculas pró (IL-6 e TNF- $\alpha$ ) e antiinflamatória (IL-10) no decorrer da sepse.O PEATE se mostrou sensível a sepse com aumento de latência da onda $V$ no desenvolver da doença no modelo experimental utilizado. O uso de Ketamina associada à xilazina influenciou o resultado do PEATE, aumentando o valor de latência absoluta da onda $V$ do PEATE.

Descritores: Potenciais auditivos evocados, potenciais auditivos evocados do tronco encefálico, sepse, isquemia, anestesia, ketamina. 


\section{SUMMARY}

LIMA JP. Auditory Brainstem Response in gerbils submitted to ischemia and sepsis. [essay]. São Paulo: Faculdade de Medicina, Universidade de São Paulo; 2012.

Introduction: The Cerebrovascular Accident of ischemic type is a clinical condition affecting thousands of people around the world. As a result of this injury we observe neuronal death, and along the natural course of recovery individuals may develop sepsis. Sepsis is a systemic inflammatory response that may lead to death. Along its development, several cytokines are produced that characterize the inflammatory process on the body. To assess the clinical conditions of a patient with this condition the Auditory Brainstem Response (ABR) may be useful, as it is not an invasive procedure, it is fast to perform, and may be done at the patient's bedside. On the other hand, the ABR may be sensitive to the use of some anesthetics. Objectives: To perform an analysis of the IL-6, IL-10 and TNF- $\alpha$ cytokines in the course of sepsis; to verify the ABR latency values in gerbils submitted to ischemia and sepsis; and to verify the influence of the ketamine/xylazine anesthetic on the ABR values in these animals. Method: ABRs were collected for 72 adult male gerbils divided into 6 groups, namely: control, sepsis, ischemia, sham, ischemia with sepsis and sham with sepsis. For induction of sepsis, intraperitoneal lipopolysaccharide (LPS) was injected into the gerbils. The animals were anesthetized prior to the collections with ketamine/xylazine, theirs ABRs were collected before any procedure (base collection), after ischemia and 2, 4, 8 and 24 hours after the LPS injection. The absolute latency of the $V$ wave was assessed, and values were compared within and among groups. The IL-6, IL-10 and TNF- $\alpha$ cytokines were analyzed and compared in each study group. Results: An increase was observed in IL-6, IL-10 and TNF- $\alpha$ cytokines in the course of sepsis. There was a statistically significant difference in the groups submitted to sepsis in the value of the $\mathrm{V}$ wave latency compared to the other groups. An increase in the $V$ wave latency was also observed after successive injection of the ketamine/xylazine anesthetic in all study groups. Conclusion: There was an increase in the levels of IL-6, IL-10 and TNF- $\alpha$ cytokines in the animals injected with LPS, revealing a change of the gene expression of the pro- (IL- 6 and TNF- $\alpha$ ) and anti-inflammatory (IL-10) molecules in the course of sepsis. The ABR proved to be sensitive to sepsis with an increase of the $V$ wave latency in the course of the disease on the experimental model used. The use of ketamine/xylazine influenced the results of the $A B R$, increasing the absolute latency value for the $V$ wave of the ABR.

Descriptors: Auditory evoked potential; auditory brainstem response; sepsis; ischemia; anesthetics; ketamine. 


\section{Introdução}


Introdução

\section{Introdução}

Mundialmente milhares de pessoas são vítimas de Acidente Vascular Cerebral (AVC). O AVC do tipo isquêmico caracteriza-se pela ausência parcial ou total de oxigênio no cérebro (Lenzi et al., 1982; Joaquim et al., 2010). Essa ausência ou redução da oferta de oxigênio no cérebro promove inúmeros desarranjos que culminam em morte neuronal (Stehno-Bittel, 2008). Muitos pacientes permanecem com sequelas pós-AVC e, além disso, no decorrer natural de recuperação, o indivíduo pode desenvolver a sepse (Basile-Filho et al., 2001).

A sepse é uma resposta pró-inflamatória sistêmica exacerbada. Possui desenvolvimento complexo, que ainda não é totalmente compreendido. Essa resposta inflamatória, quando não controlada, acomete diversos órgãos, podendo, inclusive, levar o indivíduo ao óbito (Juncal et al., 2011)

Para avaliar as condições clínicas de um paciente, utilizam-se os índices prognósticos, que são um conjunto de informações obtidas por meio de exames e sinais clínicos, cujos principais objetivos são: medir alterações fisiológicas, anatômicas, orientar no prognóstico e melhorar o atendimento do paciente (Chang et al.,1998; Abdulkader, 2003).

Exames neurológicos, de imagem, avaliação neurobioquímica, análise morfológica e investigação eletrofisiológica são alguns dos possíveis recursos na tentativa de obter algum índice de prognóstico. Dentro da investigação eletrofisiológica encontram-se os potenciais evocados 
Introdução

sensoriais. Esses potenciais têm as vantagens de serem rápidos, simples, não serem invasivos e poderem ser feitos à beira do leito (Nakabayashi et al., 2001).

Os potenciais evocados auditivos (PEA) pertencem a esse grupo. 0 Potencial Evocado Auditivo de Tronco Encefálico (PEATE) é um teste eletrofisiológico que pode contribuir como índice de prognóstico, uma vez que analisa objetivamente a área do tronco encefálico. Outra técnica para avaliar os efeitos de doenças é a avaliação morfológica, que engloba contagem de células das áreas lesadas.

Porém, muitas vezes, o PEATE é realizado sob condição de anestesia. Sabe-se que alguns anestésicos agem sobre o Sistema Nervoso Central alterando a sinapse neuronal. A ketamina é um exemplo de anestésico. Ela interfere na ação do glutamato, diminuindo a ação desse aminoácido excitatório, que é essencial para a sobrevivência neuronal (Miyake et al., 1998).

Com essa perspectiva, estudos experimentais são de grande valia para se obter o que cada exame pode contribuir na rotina clínica. Com a maior possibilidade de diminuir variáveis, obtendo-se grupos homogêneos, é possível entender os mecanismos de funcionamento bem como os resultados encontrados. As pesquisas in vivo fornecem respostas que métodos artificiais não expressam, e elas têm como finalidade a cura e o bem-estar do ser humano. As pesquisas realizadas com animais antecedem o uso em humanos, diversos avanços na área da saúde estão relacionados 
Introdução

com a pesquisa em animais, incluindo recursos terapêuticos e diagnósticos laboratoriais e de imagem (Seelig, 2007).

Muitas são as pesquisas com PEA realizadas em animais. Estudos envolvendo isquemia e PEATE verificaram alteração na latência de ondas pós-isquemia (Sohmer et al., 1984; Inui et al., 1995). Estudos envolvendo sepse e PEATE não foram encontrados na literatura até o momento de finalização deste estudo. Quanto ao uso de anestésico foram encontradas diferentes conclusões a respeito da influência da ketamina nos valores do PEATE (Bobin et al., 1979; Sims e Horohov, 1986; Van Looij et al., 2004).

Este estudo tem como finalidade verificar os valores de latência do PEATE em gerbils submetidos à isquemia e sepse, fazer uma análise morfológica (análise das citocinas) e verificar a influência do anestésico ketamina associado à xilazina nos valores do PEATE desses animais. A hipótese que norteou este estudo foi a de que o PEATE seria capaz de identificar gerbils com isquemia e sepse, e que a anestesia não influenciaria nos valores de latência do PEATE. 
Objetivos 
Objetivos

\section{Objetivos}

2. Objetivo Geral

O objetivo geral deste estudo foi verificar o Potencial Evocado Auditivo de Tronco Encefálico em gerbils com isquemia e sepse, buscando correlacionar a mudança do potencial nessas situações induzidas e avaliar o PEATE como um fator de prognóstico para esses casos.

\section{Objetivos Específicos}

Especificamente, os objetivos são:

-verificar o nível de citocinas no sangue dos animais;

- verificar os valores de latência do PEATE nas seguintes condições: pré e pós isquemia, pré e pós sepse, comparando com um grupo controle e um grupo sham;

- verificar a influência do anestésico Ketamina associado à xilazina no PEATE. 
Revisão de Literatura 


\section{Revisão de Literatura}

\subsection{Acidente vascular cerebral isquêmico}

O Acidente Vascular Cerebral (AVC) é uma interrupção sanguínea no cérebro e ocorre quando uma artéria que fornece sangue fica bloqueada ou se rompe. Isso pode provocar uma lesão cerebral e alterações nas funções neurológicas (O’Sullivan, 1993).

O AVC pode ser dividido em três grupos: acidente vascular cerebral isquêmico $(\mathrm{AVCl})$, hemorragia intracelular e hemorragia subaracnóide (Abe, 2010). O AVCI é caracterizado pela ausência ou redução acentuada na oferta de oxigênio no cérebro (Duarte, 2003). A isquemia pode ser classificada como: global ou focal, quando há falta total ou parcial fornecimento de oxigênio; e em completa e incompleta, quando há ou não reperfusão , ou seja, retorno do fluxo sanguíneo vascular (Lenzi et al., 1982; Joaquim et al., 2010).

A ausência de oxigênio nos neurônios acarreta morte neuronal. Além disso, durante a isquemia e a reperfusão há a excitação excessiva de neurônio, fenômeno conhecido como excitotoxicidade, que é causada pelo excesso de liberação de glutamato pelos neurônios privados de oxigênio. Esse aumento de liberação de glutamato é responsável pela morte de neurônios pós-sinápticos, já que o glutamato em concentração excessiva é tóxico para os neurônios (Zipfel et al., 1999; Stehno-Bittel, 2008). 
O glutamato liberado na fenda sináptica liga-se ao receptor do tipo NMDA (N-metil-D-aspartato) na membrana celular, o que promove o influxo de cálcio $\left(\mathrm{Ca}^{2+}\right)$ para dentro da célula e a liberação de reservas internas de $\mathrm{Ca}^{2+}$ Com o aumento de $\mathrm{Ca}^{2+}$ dentro da célula, ocorre a saída de potássio $\left(\mathrm{K}^{+}\right)$para fora da célula, o que causa um aumento da glicólise para a bomba de sódio potássio $\left(\mathrm{Na}^{+}-\mathrm{K}^{+}\right)$, para o transporte de $\mathrm{K}^{+}$para dentro da célula. A glicólise e o aumento de $\mathrm{Ca}^{2+}$ no interior da célula promovem eventos que geram a destruição dos neurônios, entre eles: liberação de ácido aracdônico (AA) e produção de radicais livres de oxigênio (Stehno-Bittel, 2008).

Os receptores metabotrópicos de glutamato também são ativados, ocasionando mensagens secundárias ao sistema, que inclui ativação de fosfolipase $\mathrm{D}$, regulação da formação de cAMP (adenosina monofosfato cíclico) e modulação de canais de íons que, em conjunto com os outros acontecimentos poderão causar morte celular. Há também a inibição dos fatores de crescimento neuronal que estão intimamente ligados à regulação do adequado funcionamento celular, entre eles insulina, fator de crescimento de fibroblasto e fator de crescimento do nervo. A inibição desses fatores pode ocasionar apoptose neural (White, 2000).

O processo de reperfusão também é tóxico para a célula (Campos e Yoshida, 2004), isso porque ocorre formação de radicais livres (Castro e Silva Junior et al., 2002) e peroxidação de lipídios (Krause et al., 1988) no processo de reoxigenação.

Após uma lesão cerebral, o indivíduo pode permanecer com diversos tipos de sequelas, entre elas estão a hemiplegia (paralisia completa de um 
Revisão de Literatura

lado do corpo), hemiparesia (fraqueza de um lado do corpo), alteração de cognição, aprendizado, memória, atenção e linguagem, além de possíveis problemas emocionais.

Além disso, no processo natural de recuperação o indivíduo pode desenvolver um quadro de disfunção de órgãos do tipo sequencial. O quadro inicial é conhecido por provocar alterações do estado de consciência, taquipneia e febre. As razões dessa transição não estão completamente definidas, mas acredita-se que o processo de base não consiga ser resolvido e um quadro de resposta excessiva pelo organismo se instale (Basile-Filho et al., 2001).

Diversas pesquisas têm sido feitas para descobrir não só a fisiologia da isquemia, mas também meios para a reabilitação (Gorbunov et al., 2010; Aquilani et al., 2011). As pesquisas experimentais têm um papel importante nesse campo, uma vez que dentro de condições laboratoriais é possível manipular melhor as variáveis do quadro isquêmico. As pesquisas experimentais utilizam diversos tipos de animais, sendo que o mais utilizado é o gerbil da Mongólia (Meriones Unguiculatus). Esse animal não possui o Polígono de Willis, e com isso o fornecimento de sangue cerebral ocorre exclusivamente pela artéria carótida comum (Levine e Shon, 1969). Portanto, com a oclusão da carótida nesse animal, tem-se um ótimo modelo para isquemia cerebral global. 
Revisão de Literatura

\subsection{Sepse}

A sepse é uma resposta inflamatória sistêmica a uma infecção grave, que frequentemente acomete pacientes que se encontram em unidades de terapia intensiva (UTIs), causando elevado número de mortalidade nesses pacientes debilitados (Soriano e Silva, 2007). No decorrer da sepse vários eventos acontecem ao mesmo tempo, por isso, às vezes na prática clínica é difícil observar uma progressão linear. Muitos pacientes desenvolvem choque séptico muito rapidamente (Lomar, 2007).

É uma doença definida por critérios clínicos. Em 1991 o American College of Chest Physicians e a Society of Critical Care Medicine estabeleceram alguns critérios de diagnóstico e nomenclatura da sepse e outras comorbidades (Pereira Junior, 1998; Silva, 2007a). A seguir serão citadas as nomenclaturas definidas, assim como o quadro clínico associado:

Síndrome da resposta inflamatória sistêmica (SIRS): resposta inflamatória sistêmica a uma grande variedade de condições clínicas severas. Caracteriza-se pela presença de pelo menos dois dos seguintes parâmetros: hipotermia (temperatura corpórea menor que $36^{\circ} \mathrm{C}$ ) ou febre (temperatura corpórea maior que $38^{\circ} \mathrm{C}$ ); taquicardia (frequência cardíaca acima de 90 bpm); taquipneia (frequência respiratória acima de 20ipm ou $\mathrm{pCO}^{2}$ abaixo de $32 \mathrm{mmHg}$ ); leucocitose (leucócitos acima de $12 \times 10^{9}$ células/L); leucopenia (abaixo de $4 \times 10^{9}$ células/L ou mais do que $10 \%$ de células imaturas); 
Sepse: resposta inflamatória sistêmica à infecção;

Sepse Severa: sepse associada com disfunção orgânica, hipoperfusão e hipotensão, com possível presença de acidose láctica, oligúria, alteração aguda do estado mental;

Choque Séptico: sepse na presença de hipotensão, irresponsiva à hidratação vigorosa, associada à disfunção orgânica e anormalidades de perfusão.

Síndrome de insuficiência de múltiplos órgãos: presença de função anormal de três ou mais órgãos em paciente crítico que necessitam de suporte para manter a homeostasia.

A taxa de mortalidade de pacientes acometidos com SIRS e sepse é elevada no mundo inteiro. No Brasil, foi realizado um estudo epidemiológico envolvendo 65 hospitais de todo o país. Nesse estudo observou-se 16,7\% do número de pacientes acometidos de sepse nas UTIs. A mortalidade global em 28 dias de internação foi de 46,6\%. A mortalidade na sepse, sepse severa e choque séptico foi de $16,7 \%, 34,4 \%$ e $65,3 \%$, respectivamente (Sales Júnior, 2006).

Além da invasão microbiana, a SIRS pode surgir a partir de trauma, queimadura, pancreatite, pós-operatório de cirurgia cardíaca, rabdomiólise (Cotran et al., 2000). Para um melhor entendimento usaremos o modelo de invasão microbiana para explicar o mecanismo da sepse.

A fisiopatologia da sepse é complexa e varia conforme a resposta do hospedeiro e as características do organismo infectante (Henkin, 2009). É um processo que envolve alteração local e sistêmica, que ainda não está 
totalmente esclarecida. Sabe-se, porém, que ocorre uma inflamação excessiva do organismo, que por meio de feedbacks positivos e respostas sinérgicas de vários sistemas, há a potencialização da inflamação sem controle. Serão citadas as principais alterações presentes no quadro séptico.

O sistema imune inato é a primeira linha de defesa do organismo. Entre outras funções, esse tipo de sistema abrange: fagocitose de bactérias, resistência da pele à invasão por microorganismos e presença de substâncias na corrente sanguínea capazes de destruir microorganismos estranhos ou toxinas. A imunidade inata engloba as proteínas do sistema complemento, proteínas da fase aguda, monócitos, macrófagos, granulócitos, células dendríticas e linfócitos "natural killer". Os neutrófilos e os macrófagos são os principais tipos de células do sistema imune inato (Mussi-Pinhata e Rego, 2005).

Esse sistema reconhece os organismos invasores através de receptores que podem estar na superfície celular, nos compartimentos intracelulares ou por meio de substâncias secretadas no sangue ou nos fluidos teciduais.

Essas estruturas presentes nos patógenos que provocam 0 reconhecimento nas células do sistema imune inato são conhecidas como PAMPs (padrões moleculares associados a patógenos - pathogenassociated molecular patterns) (Kortgen et al., 2006). O lipopolissacarídeo (LPS) das bactérias gram-negativas é um exemplo de PAMPs e é reconhecido pelos receptores CD14 e os Toll-like (TLR) presentes no sistema imune inato (Fock, 2005). 
Quando o LPS liga-se ao CD14, que é encontrado na membrana de macrófagos, há uma ativação celular. Esse sinal de ativação é realizado por meio de um receptor do tipo transmembrana presente na célula-alvo, o TLR4 (Cohen, 2002; Russel, 2006). Juntamente com a molécula MD-2, também presente nessa célula, forma-se um complexo TLR-4/MD-2, que aumenta a sensibilidade do LPS e desencadeia o sinal de ativação celular. Depois disso, ocorre uma cascata de ativação até a mobilização do fator nuclear de transcrição kappa B (NF-kB), que tem como papel promover a expressão gênica de moléculas pró-inflamatórias, como fator de necrose tumoral alfa (TNF- $\alpha$ ), interleucinas (ILs) e diversas citocinas pró e anti-inflamatórias (Baldwin Jr., 2001; Tak e Firestein, 2001).

O TNF- $\alpha$ que é produzido por macrófagos, células dendríticas, neutrófilos, células endoteliais e linfócitos T (Bilate, 2007), é a primeira citocina liberada em resposta ao LPS. Seus efeitos deletérios estão relacionados à hipotensão, aumento da permeabilidade vascular, anorexia, dano à mucosa intestinal, hiperglicemia e ação direta no hipotálamo e hiperpirexia.

Há diversas ILs liberadas no processo inflamatório durante a sepse, as principais são: IL-1, IL-6 e IL-10.

A IL-1 possui duas formas diferentes, a IL-1a e IL-1 $\beta$, ambas possuem efeitos sinérgicos e semelhantes ao TNF- $\alpha$ e são produzidas por monócitos, macrófagos, células endoteliais, epiteliais e pelo próprio TNF- $\alpha$ (Opal e DePalo, 1999, Bilate, 2007). Juntamente com o TNF- $\alpha$ a IL-1 $\beta$ é 
capaz de amplificar a resposta imune inata e ativar o sistema imune adaptativo (Clausell e Brauner, 1999).

A IL-6 é induzida pelo TNF- $\alpha$ e IL-1 e possui, como outras citocinas, papel pró e anti-inflamatório. É um potente indutor de proteínas da chamada fase aguda, além de promover a liberação de células B e secreção de anticorpos (Ac) (Opal e DePalo, 1999).

A IL-10 produzida por macrófagos, células dendríticas, linfócitos T reg, é um potente inibidor do linfócito Th1, ou seja, é uma citocina antiinflamatória. Age também nos monócitos e macrófagos na síntese próinflamatória. É sintetizada por monócitos e células B (Bilate, 2007; Opal e DePalo, 1999).

Existem outras citocinas produzidas durante a resposta séptica que possuem basicamente efeitos de feedbacks positivos, potencializando assim, ainda mais o processo inflamatório.

Entre os principais eventos que se observam com a excessiva produção de citocinas pró e anti-inflamatórias temos a ativação de moléculas de adesão, aumento do ácido aracdônico (AA), radicais livres de oxigênio, óxido nítrico (NO) e fator de ativação plaquetário (PAF). Todo esse descontrole de substâncias ocasiona um mau funcionamento dos órgãos vitais. Observa-se no processo da sepse o comprometimento sistêmico do organismo. A Figura 1 mostra resumidamente os eventos durante a sepse. 
Modelo de invasão microbiana:

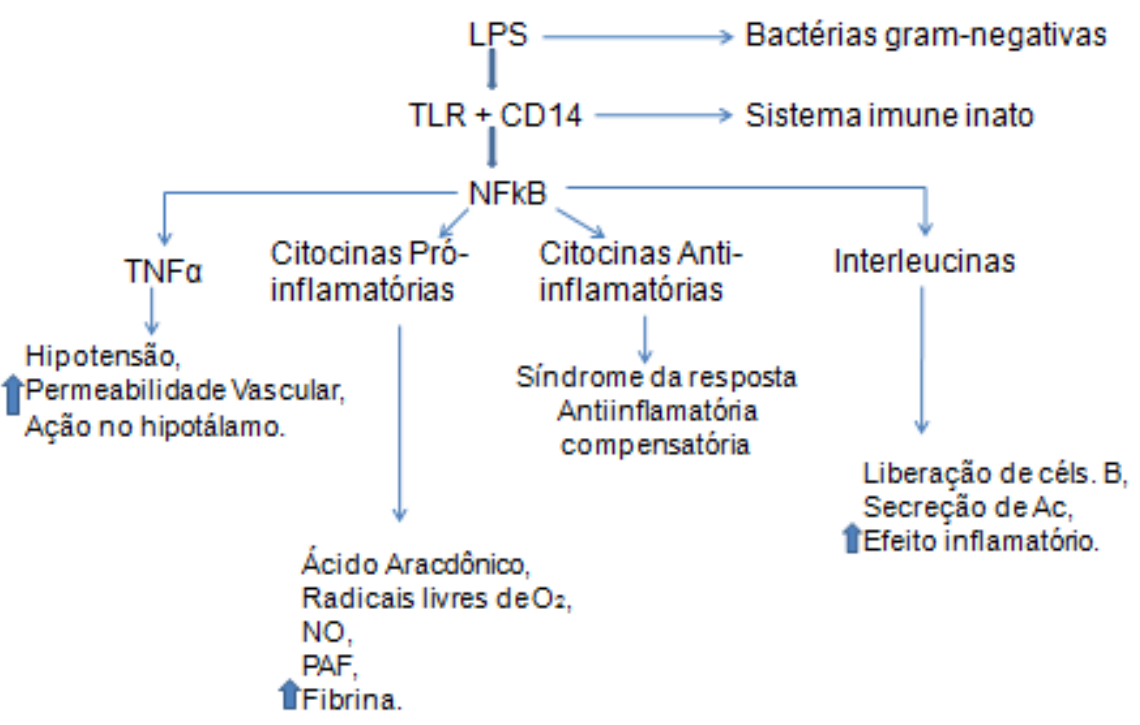

Figura 1: Modelo de invasão microbiana na sepse (Henkin et al., 2009).

Em relação ao sistema nervoso central (SNC), as modificações dos níveis de citocinas na sepse podem comprometer o funcionamento cerebral, ocasionando um quadro conhecido como encefalopatia séptica. A alteração na permeabilidade da barreira cerebral sanguínea e o processo inflamatório acarretam alterações de inúmeras substâncias no SNC, o que pode levar alteração do estado mental do paciente. O LPS no cérebro ativa substâncias que induzem a produção de interleucinas (IL-1 e IL-6), TNF- $\alpha$, NO sintetase, e por meio dos astrócitos, há um aumento da quantidade de prostaglandinas E. Conjuntamente, as microglias aumentam a expressão de receptores de prostaglandinas. $\mathrm{O} \mathrm{NO}$, as citocinas e as prostaglandinas modulam a neurotransmissão cerebral (Silva, 2007b), portanto na presença de um desequilíbrio dessas substâncias, podem ocorrer alterações de 
funcionamento cerebral. O aumento das citocinas inflamatórias, como a IL-1, IL-6 e TNF- $\alpha$ está associado a alterações do comportamento, tais como prejuízo cognitivo, depressão e anorexia (Dantzer et al., 2000). O TNF-a também está relacionado à apoptose celular (Hotchkiss et al., 2002).

Foram observados quadros de hemorragia cerebral, hipercoagulabilidade, microabcessos e ainda leucoencefalopatia multifocal necrotizante no paciente séptico (Sharshar et al., 2004; Sharshar et al., 2005). Além disso, essa alteração de permeabilidade da barreira hematoencefálica, em conjunto com as alterações hemodinâmicas, pode contribuir para a ocorrência de isquemia cerebral (Bowton et al., 1989; Booke et al., 2003).

Na tentativa de controlar todo esse aumento de produção de citocinas inflamatórias, o organismo também pode desencadear uma resposta exagerada de diversas citocinas antagonistas àquelas inflamatórias, ou seja, citocinas anti-inflamatórias. Quando isso ocorre de forma exagerada, aumentam-se também as infecções secundárias, que caracterizam o quadro de síndrome da resposta anti-inflamatória compensatória (Holub, 2007).

Com todas essas alterações, a sepse promove o comprometimento do equilíbrio de sistemas e órgãos, acarretando doenças miocárdicas, hemodinâmicas, circulatórias, respiratórias, renais, intestinais, hormonais e neurológicas. 


\subsection{Sistema Auditivo}

O sistema auditivo é dividido anatomicamente em periférico e central. A última estrutura do sistema auditivo periférico é o nervo auditivo (NA). O NA possui dois tipos de fibras, as do tipo I, que correspondem a $90 \%$ do total de fibras, são mais mielinizadas e fazem conexão com as células ciliadas internas. Já as do tipo II correspondem a 10\%, são menos mielinizadas do que as do tipo I e fazem conexão com as células ciliadas externas. O NA possui uma organização tonotópica, ou seja, fibras que respondem melhor para sons de alta, média e baixa frequência (Spoendlin, 1972).

\subsection{A. Sistema Nervoso Auditivo Central}

O núcleo coclear (NC) é a primeira estação auditiva central. O NC possui três divisões: dorsal, ventral posterior e ventral anterior. Possui diferentes tipos celulares, sendo que cada grupo parece estar relacionado a uma função específica que se divide em codificar, reter e transmitir as características de frequência, intensidade e duração do estímulo sonoro (Balen, 1997; Ferés e Cairasco, 2003).

A estrutura seguinte é o complexo olivar superior (COS). O COS possui células multi e bipolar e basicamente duas divisões anatômicas: a lateral e a medial. A tonotopia continua preservada nessa estrutura. É o primeiro local onde há representação bilateral do sinal acústico. O COS é 
sensível à diferença temporal e de intensidade entre as orelhas, dessa maneira, essa estrutura está relacionada às funções auditivas de fusão, lateralização e localização sonora (Joris e Yin, 1995).

Após o COS, vem o lemnisco lateral (LL), com duas divisões: núcleo dorsal e núcleo ventral. Essa estrutura também é sensível à diferença de intensidade e de tempo interaural (Musiek e Baran, 2007). É a estrutura que mais contribui para a resposta da onda $V$ do potencial evocado auditivo de tronco encefálico (Möller et al., 1981).

O colículo inferior $(\mathrm{Cl})$ recebe vias ipsi e contralateralmente do LL (parte do núcleo dorsal), NC e COS, e ipsilateralmente do LL (parte do núcleo ventral) (Adams, 1979). É a primeira estrutura sensível a duração do estímulo sonoro (Faure et al., 2003). O Cl possui neurônios que respondem a estímulos contralaterais, monoaurais e binaurais e neurônios que respondem à estimulação monoural de cada orelha. Dessa forma, o Cl também está associado à percepção auditiva de diferença de intensidade e de tempo (Litovsky et al., 2002).

O corpo geniculado medial (CGM) é a próxima estrutura central. Ele está localizado no tálamo. O CMG possui três divisões: medial, dorsal e ventral. Ele recebe principalmente vias ipsilaterais do $\mathrm{Cl}$. As vias neurais do CMG levam as informações para a cápsula interna, cápsula externa e área auditiva secundária, e ainda para a amígdala, onde parece haver a associação auditiva-emocional no cérebro (Musiek e Baran, 2007).

O córtex auditivo primário e secundário recebem informações do CMG, essa via é conhecida como tálamo-cortical. No córtex auditivo 
Revisão de Literatura

encontram-se vários mapas tonotópicos, que são responsáveis pelo reconhecimento das características específicas de um som. Muito embora haja os mapas tonotópicos, grande parte dos neurônios do córtex auditivo não responde a frequências específicas da cóclea. Acredita-se que ocorra uma associação de diferentes frequências sonoras entre si, ou ainda associações com outras informações provenientes de outras áreas do córtex (Guyton, 1997).

O córtex auditivo está associado à discriminação do padrão tonal, do padrão de sons sequenciais, da detecção de "gaps" e ao significado do som escutado (córtex auditivo) (Musiek e Baran, 2007).

O corpo caloso conecta os dois hemisférios cerebrais. É o maior trato de fibras no cérebro humano. Ele é composto por largos axônios mielinizados que cursam de um hemisfério para o outro. Tem função de transferir a informação auditiva de um hemisfério para o outro (Bellis, 1996).

\subsection{Potencial Evocado Auditivo (PEA)}

Os potenciais evocados auditivos (PEAs) refletem a atividade bioelétrica gerada por meio da alteração do potencial de membrana através de uma estimulação acústica. Eles podem ser classificados de acordo com: latência, sendo possível ser de curta, média e longa latência; fonte geradora (potencial coclear e do nervo coclear, tronco encefálico ou subcortical e cortical); posição dos eletrodos em relação à sua fonte geradora (campo 
Revisão de Literatura

distal ou proximal); e ainda como endógeno, que depende de alterações de resposta do indivíduo, como a atenção, ou exógeno, que depende muito mais das características do estímulo, como taxa de apresentação, intensidade e polaridade (Hall, 1992).

\subsection{A. Potencial Evocado Auditivo de Tronco Encefálico (PEATE)}

O PEATE é um conjunto de sete ondas que aparecem nos primeiros 10 ms da apresentação, portanto de curta latência, e tem como principal objetivo avaliar a integridade do tronco auditivo cerebral (Jewett e Williston, 1971).

Esse potencial pode ser captado por meio de eletrodos de superfície localizados em uma das orelhas (eletrodo de referência), na fronte (Fz), ou no topo de cabeça $(\mathrm{Cz})$ (eletrodo ativo) e eletrodo terra, que pode ser posicionado em uma das mastoides. O estímulo auditivo é apresentado por fones de inserção ou tipo concha. Estímulos com taxa de apresentação variando entre 13 a 30 pulsos por segundo são recomendados na rotina clínica. As respostas são captadas, filtradas, amplificadas e promediadas em um aparelho específico e mostradas em um computador (Hall, 1992).

É uma avaliação objetiva, pois não necessita de resposta do indivíduo. Para a realização do exame o paciente pode estar dormindo, acordado ou sedado, pois não há influência do nível de consciência (Amadeo e Shagass, 1973). 
O PEATE consiste no surgimento de sete ondas, porém clinicamente apenas as ondas I, III e V são utilizadas. Para cada onda há um local gerador e sua análise ocorre através do valor de latências absolutas e dos valores interpicos. A partir dos dois anos de idade, as respostas se assemelham à de um adulto, porém antes disso, devido ao processo maturacional ainda presente nas vias auditivas, ocorre aumento das latências absolutas e interpicos (Lauffer e Wenzel, 1990).

A onda I tem seu local de origem na porção distal do NA; a onda II, na porção proximal do NA; a onda III, nos NCs; a onda IV, no COS, e a onda V, no LL (Hashimoto et al., 1981; Moller e Jannetta, 1982; Moore, 1987).

O exame PEATE pode ter finalidade de neurodiagnóstico, ou seja, investigar a integridade do tronco encefálico; dessa forma, o exame é realizado com um som de forte intensidade $(80 \mathrm{dBnNA})$ ou pode também ter o objetivo de pesquisar o limiar eletrofisiológico, nesse caso o avaliador diminui a intensidade até onde conseguir visualizar a onda V.

Para a realização do PEATE, podem-se utilizar diversos tipos de estímulos, sendo que os mais usados são o clique e o tone burst. O estímulo clique corresponde a um estímulo transitório, de início abrupto, com curta duração que promove um disparo sincrônico dos neurônios do NA. Possui espectro entre as frequências de 1000 a 4000 Hz (Hall, 1992). Por sua vez, o tone burst é um estímulo tonal, com duração breve, que possibilita a avaliação de frequências específicas (Hyde, 1985).

O PEATE é considerado um potencial exógeno, por isso suas respostas podem ser modificadas conforme alguns parâmetros escolhidos. 
Revisão de Literatura

Sabe-se que a polaridade exerce influência na latência de onda, sendo observada uma discreta diminuição na polaridade do tipo condensada (Lima et al., 2007). A intensidade também é fator importante para os valores de latência e amplitude de onda. Observa-se aumento da latência e diminuição da amplitude conforme a intensidade diminui.

Apesar de ser considerado um potencial exógeno, sendo influenciado por diversos parâmetros, o PEATE também pode ser influenciado frente a algumas situações adversas, tais como: presença de infecção no organismo, variação de temperatura e uso de anestésico. Isso porque nessas situações pode ocorrer alteração do metabolismo e funcionamento na transmissão sináptica.

Indivíduos com quadro de infecção podem sofrer alterações sistêmicas, incluindo a expressão de diversas substâncias no organismo. Dessa maneira, pode haver alteração na transmissão de sinapses ou até mesmo no processo de apoptose de células cerebrais. Além disso, em algumas patologias, pode ocorrer presença de aumento da pressão intracraniana e a formação de abscessos, que podem comprimir áreas cerebrais. Nessas situações não é de se estranhar alguma alteração dos valores do PEATE. Em estudo com crianças com patologia cerebral, Goitein et al., 1983, relacionaram a diminuição de onda $\mathrm{V}$ com a presença de abscesso cerebral.

A sepse que é um quadro de inflamação sistêmica também pode alterar as transmissões sinápticas e promover quadros de encefalopatia cerebral, como já citado anteriormente. Os trabalhos envolvendo os 
Revisão de Literatura

potenciais evocados auditivos e sepse são escassos na literatura, principalmente envolvendo PEATE.

Zauner et al., 2002, estudaram os potenciais somatossensoriais cortical (N20-N70) e subcortical (N13-N20) para avaliar a incidência da encefalopatia séptica em pacientes com sepse severa e choque séptico. A conclusão encontrada pelo grupo foi que esses potenciais são sensíveis para esse tipo de avaliação e o prejuízo dos mesmos esteve associado à severidade da doença.

Em outro estudo de 2008, Rinaldi et al. também utilizaram os PEAs de média latência para identificar encefalopatia em pacientes sépticos, usando as mudanças do $A$-line autoregression Index ( $A A I)$. Os autores encontraram diferença estatisticamente significante nos grupos com sepse em relação ao grupo controle sem sepse.

Até a finalização deste trabalho, não foi encontrada literatura relacionando PEATE e sepse.

O PEATE também tem sido utilizado em eventos neurológicos, como a isquemia. Em 1984, Sohmer et al. verificaram a presença da onda I e ausência das demais ondas no PEATE em gatos submetidos à isquemia através da oclusão da carótida comum. Eles avaliaram o PEATE logo após o procedimento cirúrgico. Em 1987, Cowen et al. submeteram gerbils à oclusão da carótida central. Eles observaram diminuição de amplitude dos potenciais evocados somatossensoriais e aumento da condução de tempo no EP-P11 e nenhum efeito de condução de tempo em EP-P3. No processo de reperfusão foi observada diferença estatisticamente significante de 
Revisão de Literatura

resposta após 4 horas, com aumento de amplitude nos potenciais somatossensoriais.

Em 1995 Inui et al. verificaram as latências das ondas do PEATE após a oclusão da artéria cerebelar ântero-inferior em ratos nos tempos de 0, 6, 15, 30 e 60 minutos. Eles encontraram três achados distintos: ausência total de resposta, aumento de latências das ondas I e IV e ainda, ausência de respostas seguida de ressurgimento de ondas. Os autores afirmaram que tal fato pode estar associado com à taxa de irrigação sanguínea na cóclea.

Com relação à anestesia, existem diversos tipos de drogas com diferentes mecanismos de ação que são capazes de deprimir o sistema nervoso central (SNC). Estudos relatam pouca ou nenhuma interferência nos valores do PEATE com uso dos barbitúricos (Sutton et al., 1982), e com uso de hidrato de cloral, sendo que este é amplamente usado na rotina clínica (Palaskas et al., 1989). Os barbitúricos assim como a maioria dos benzodiazepínicos, deprimem o SNC, aumentam a ação do GABA (GammaAminoButyric Acid), que via de regra, é um neurotransmissor inibitório.

Porém, outros anestésicos possuem diferentes mecanismos de ação, como a ketamina, por exemplo. Esse composto age como antagonista não competitivo do receptor NMDA, um dos receptores do glutamato. A ketamina interfere na ação desse aminoácido excitatório, bloqueando o canal aberto e/ou ligando-se ao canal fechado, causando uma diminuição na freqüência de abertura do canal. Com isso, há uma diminuição da ação do glutamato, que é essencial para a sobrevivência neuronal (Miyake et al., 1998). 
Os estudos envolvendo PEATE e o uso de Ketamina (Ketalar) associada ou não à xilazina (Rompun) são controversos.

Bobbin et al., 1979, compararam o uso de ketamina $(100 \mathrm{mg} / \mathrm{kg})$, pentobarbital $(50 \mathrm{mg} / \mathrm{kg})$ e solução salina $(1 \mathrm{~mL} / \mathrm{kg})$ em ratos. Nesse estudo não foi observada diferença significante nas ondas no PEATE pré e pósinjeção dos anestésicos em ratos. Cohen e Brite, 1982, não encontraram diferença de latência entre os anestésicos pentobarbital (40mg/kg), ketamina (44mg/kg), halotano e cloralose $(50 \mathrm{mg} / \mathrm{ml})$, em gatos submetidos à avaliação do PEATE a 90dBnNA. O mesmo foi observado por Goss-Sompson e Kriss, em 1991, que compararam o uso de ketamina $(90 \mathrm{mg} / \mathrm{kg})$ associado à xilazina $(10 \mathrm{mg} / \mathrm{kg})$ e pentobarbital $(40 \mathrm{mg} / \mathrm{kg})$ em ratos durante 70 minutos após aplicação das drogas. Também não houve diferença nos resultados de ondas do PEATE em nenhum grupo.

Em contrapartida, outros estudos revelam alteração de latências das ondas do PEATE com o uso da ketamina.

Em 1986, Sims e Horohov relataram aumento das latências das ondas III e IV após 5 e 35 minutos e aumento da onda V após 5, 10, 25 e 35 minutos depois da injeção de dose de ketamina $(10 \mathrm{mg} / \mathrm{kg})$ e xilazina $(1 \mathrm{mg} / \mathrm{kg})$, em gatos.

Church e Gritzke, em 1987, estudaram a influência de injeção de duas doses de ketamina $(100 \mathrm{mg} / \mathrm{kg})$ e duas doses de solução salina em ratos em PEATE nas intensidades de 70, 90 e 110 dBnNA. Eles observaram sucessivo aumento de latência após as doses de ketamina em todas as intensidades realizadas. Notaram, também, mudança de amplitude nesse 
mesmo grupo. Por outro lado, o grupo submetido à injeção de solução salina não demonstrou mudança significante.

Em 1988, Smith e Mills avaliaram o PEATE com tone burst em gerbils adultos antes (situação de alerta) e após o uso de ketamina (50mg/kg), associada à xilazina $(1 \mathrm{mg} / \mathrm{kg})$, (sob anestesia). Eles observaram discreto aumento da latência absoluta da onda P6 (onda VI) e aumento de amplitude das ondas P4 e P6 (ondas IV e VI) nos registros dos animais quando em situação de anestesia. Os efeitos da anestesia na latência foram independentes da frequência do estímulo.

Van Looij et al., 2004, também constataram aumento de latências absolutas e interpicos no PEATE em ratos sob anestesia de ketamina $(120 \mathrm{mg} / \mathrm{kg})$ e xilazina $(7.5 \mathrm{mg} / \mathrm{kg})$ quando comparados aos resultados do animal em situação de alerta (acordado) a 90dBnNA e, também, diferença na pesquisa de limiar entre os ratos com e sem anestesia. Os que estavam sob condição de anestesia apresentaram limiares maiores dos que os que estavam acordados.

Em humanos, Norrix et al.(2012), compararam a latência de ondas do PEATE em criança sob anestesia de sevoflurance com outro grupo controle submetido à avaliação do PEATE sem sedativo. Eles encontraram diferença significante na latência da onda $V$ e aumento de latências interpicos I-III / I-V / III-V no PEATE das crianças anestesiadas. 
Métodos

\section{Métodos}

O presente estudo teve aprovação da Comissão de Ética para Análise de Projetos de Pesquisas da Diretoria Clínica do Hospital das Clínicas e da Faculdade de Medicina da Universidade de São Paulo (parecer n 0456/09). A pesquisa foi realizada no Laboratório de Investigação Médica em Emergências Clínicas da Faculdade de Medicina da Universidade de São Paulo (anexo A).

\subsection{Modelo Experimental}

Os animais utilizados foram 72 gerbils (Meriones unguiculatus), machos pesando entre 56 e $79 \mathrm{~g}$ (média de peso de $69 \mathrm{~g}$ ), entre três e cinco meses de vida, mantidos em condições ambientais controladas com ciclo claro/escuro (12/12 horas), temperatura na faixa de $22^{\circ}$ a $27^{\circ} \mathrm{C}$, umidade de 45 a $65 \%$ e ambiente higienizado, recebendo ração própria comum e água ad libitum, provenientes do biotério do Departamento de Clínica Médica da Faculdade de Medicina da Universidade de São Paulo.

A razão para a utilização destes roedores foi por apresentarem uma falha na formação do polígono de Willis que determina uma irrigação única para $80 \%$ do parênquima cerebral. Dessa forma, a preparação cirúrgica do modelo experimental fica limitada à oclusão temporária das carótidas, 
Métodos

eliminando complicações desnecessárias e produzindo um resultado muito mais consistente.

Os animais foram divididos em seis grupos experimentais, sendo que cada grupo foi composto por doze animais:

1) SHAM (sem oclusão das carótidas);

2) ISQUEMIA (com oclusão das carótidas);

3) SEPSE;

4) SHAM COM SEPSE

5) ISQUEMIA COM SEPSE;

6) CONTROLE (sem nenhum tipo de procedimento).

4.2. Procedimentos de Isquemia e Sepse

Para o procedimento da isquemia, os gerbils foram anestesiados com halotano $3 \%$ em mistura gasosa de oxigênio $30 \%$ e óxido nitroso $70 \%$ e submetidos à isquemia cerebral global por 7 minutos com oclusão bilateral das carótidas. As artérias carótidas foram expostas através de incisão mediana, para o clampeamento utilizando um tubo de polietileno através de um tubo de duplo lúmem fixado com clamps (Figura 2).

Durante o período de isquemia (7 minutos) e seguido o período de reperfusão (30 minutos) os animais foram monitorados e mantidos em temperatura controlada de $36,0 \pm 0,2^{\circ} \mathrm{C}$. Em seguida os animais foram mantidos com ração e água ad libitum. 
Métodos

Os grupos shams passaram pelo procedimento cirúrgico, porém não sofreram a oclusão das carótidas.

Esses dois grupos de animais realizaram o procedimento cirúrgico no primeiro dia de experimento.

Em relação aos grupos com sepse, no segundo dia de experimento, ou seja, 24 horas após a isquemia, foi injetado $1 \mathrm{mg} / \mathrm{kg}$ de Lipopolissacarídeo - LPS - de Escherichia Coli serotype 026: B6 (SIGMA) por via intraperitoneal, induzindo dessa maneira inflamação (sepse) no animal.

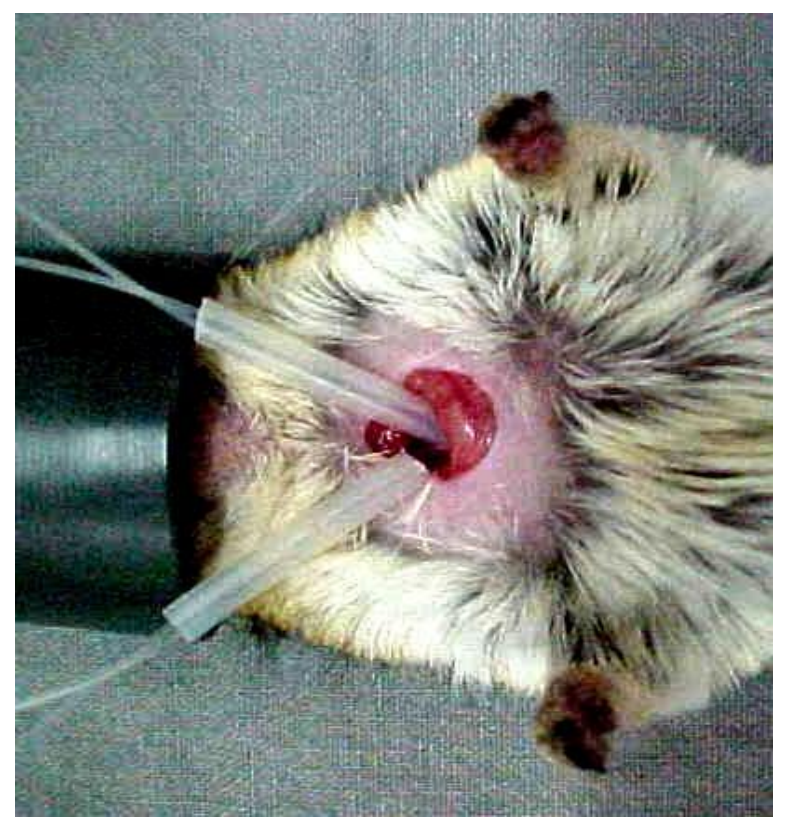

Figura 2: Procedimento de isquemia realizado no gerbil. 
Métodos

\subsection{Avaliação Eletrofisiológica}

Para a avaliação eletrofisiológica utilizou-se o equipamento da marca Biologic, modelo Navigator de dois canais. Os estímulos foram apresentados mediante fones de inserção 3B, posicionados na orelha esquerda dos animais, permanecendo a orelha direita não ocluída. A estimulação exclusiva da orelha esquerda foi escolhida por causa da inserção cirúrgica que foi feita pelo lado direito do animal.

Antes de todos os registros, os animais foram anestesiados com injeção peritoneal de Ketamina (Parke-Davis, São Paulo, Brasil)- 100 mg/kg de peso do animal e Rompun, princípio ativo: xilazina (Bayer healthCare, São Paulo, Brasil) - $4 \mathrm{mg} / \mathrm{kg}$ do peso do animal, protocolo esse já utilizado pelo grupo do laboratório de Emergências Clínicas.

O PEATE foi registrado mediante a utilização de três eletrodos, posicionados em Cz (de acordo com o sistema internacional 10-20), mastóide esquerda M1 (Jasper, 1958) e eletrodo terra. A mastoide esquerda foi utilizada como referência e a pata do animal foi utilizada para o eletrodo terra. Os animais permaneceram em uma situação de escuta passiva (Figura 3). 
Métodos

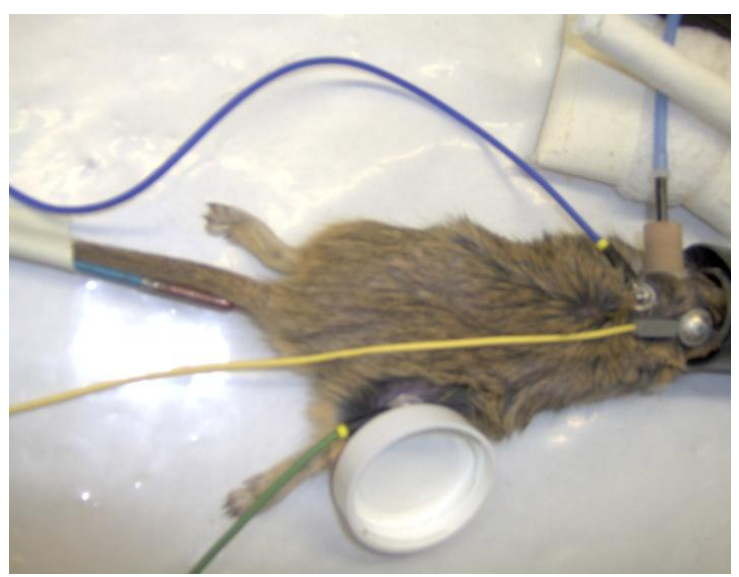

Figura 3: Captação do Potencial Evocado Auditivo.

Antes da colocação dos eletrodos, os pelos foram retirados, e uma pasta eletrolítica foi aplicada à pele dos animais, para propiciar uma melhor impedância. Após os eletrodos terem sido posicionados, a impedância foi checada, sendo mantida em um nível inferior a $5 \mathrm{~K} \Omega$.

Primeiramente foi realizada uma avaliação eletrofisiológica (PEATE) antes de qualquer procedimento para que essas medidas servissem como linha de base para todas as outras que foram realizadas (coleta pré, realizada no $1^{\circ}$ dia de experimento).

Foram, então, realizadas as coletas do PEATE nos seguintes períodos:

1- 24 horas após a isquemia - $2^{\circ}$ dia de experimento -coleta $A$;

2- duas, quatro e oito horas após a aplicação de LPS - $2^{0}$ dia de experimento, coletas $B, C$ e $D$, respectivamente;

3- 24 horas após aplicação do LPS - 3ำ dia de experimento - coleta E; 
Métodos

A Figura 4 mostra as fases de registro do PEATE bem como a ordem dos procedimentos utilizados.

\begin{tabular}{|c|c|c|c|}
\hline & Animal sem nenhum procedimento & $1^{\circ} \mathrm{dia}$ & Coleta Pré \\
\hline $\begin{array}{l}\text { Procedimento de } \\
\text { Isquemia,quando necessário }\end{array}$ & 24 horas após a isquemia & $2^{\circ}$ dia & Coleta A \\
\hline \multirow{4}{*}{$\begin{array}{l}\text { Aplicação de LPS, } \\
\text { quando necessário }\end{array}$} & 2 horas a pós LPS & $2^{\circ} \mathrm{dia}$ & Coleta B \\
\hline & 4 horas a pós LPS & $2^{\circ}$ dia & Coleta C \\
\hline & 8 horas após LPS & $2^{\circ}$ dia & Coleta D \\
\hline & 24 horas após LPS & $3^{\circ}$ dia & Coleta E \\
\hline
\end{tabular}

Figura 4: Registro das coletas do PEATE.

Os resultados foram comparados nas situações pré e pós-realização do evento isquêmico e aplicação do LPS, sendo que cada animal foi seu próprio controle, além da comparação de cada um dos animais ao grupo sham e grupo controle, ou seja, foram realizadas comparações intra e intergrupos.

Este estudo foi duplo cego, ou seja, os animais não foram identificados no grupo em que pertenciam durante a coleta do PEATE.

\subsubsection{PEATE}

Para a captação do PEATE foram utilizados 2000 estímulos do tipo clique com polaridade rarefeita e velocidade de apresentação de 13 
Métodos

estímulos por segundo, intensidade de $80 \mathrm{dBnNA}$ e fone de inserção. As respostas foram captadas, amplificadas, digitalizadas, promediadas, filtradas utilizando-se um filtro passa/baixo de $100 \mathrm{~Hz}$ e um filtro passa/alto de 1500 Hz. A janela de registro utilizada foi de 10.66 ms posterior à estimulação. Todas as respostas foram reproduzidas garantindo, assim, a reprodutibilidade do potencial adquirido.

A faixa de audibilidade do animal utilizado encontra-se entre $1 \mathrm{e}$ $20 \mathrm{KHz}$ (Ryan, 1976), dessa maneira, o clique mostra-se eficiente para a avaliação da audição nesses animais.

Para a avaliação do PEATE foi apenas considerada a onda V.

\subsection{Extração de RNA e PCR em Tempo Real}

A análise das citocinas realizada neste trabalho se deve ao fato de que foi utilizado como modelo experimental o gerbil. Os níveis de citocinas na sepse já estão bem estabelecidos no rato Wistar, porém para o gerbil ainda não há um protocolo bem definido, portanto foi necessário avaliar as citocinas como uma forma de caracterizar os grupos estudados.

Para a análise das citocinas, utilizou-se o método de extração de RNA (Ácido ribonucleico) e PCR (do inglês, Polymerase Chain Reaction) em tempo real. Tal método permite a quantificação das amostras amplificadas em tempo real, dessa maneira, obtêm-se níveis de expressão gênica quantitativamente (Novais e Pires-Alves, 2004).

Realizou-se a extração de RNA das células (leucócitos) do sangue utilizando $1 \mathrm{ml}$ do reagente TRIzol®. Neste foi adicionado $200 \mu \mathrm{de}$ 
Métodos

clorofórmio, seguindo-se vigorosa homogeneização por 15 segundos e incubação à temperatura ambiente por 3 minutos. A separação de fases foi feita por centrifugação a $12.000 \mathrm{~g}$ por 15 minutos a 4ํㅡㄴ C. O RNA presente na fase aquosa (superior) foi transferido para outro tubo e precipitado pela adição de $0,5 \mathrm{~mL}$ de isopropanol por 10 minutos à temperatura. Posteriormente, a amostra foi centrifugada a $12.000 \mathrm{~g}$ por 10 minutos a $4^{\circ} \mathrm{C}$. O sedimento foi lavado com $1 \mathrm{~mL}$ de etanol a $75 \%$ (com uso do vortex), centrifugado a $7.000 \mathrm{~g}$ por 5 minutos, seco à temperatura ambiente e ressuspenso em água tratada com DEPC (dietilpirocarbonato).

Para a quantificação dos RNAs as amostras foram diluídas em água DEPC (diluição 1:100) e a absorbância da amostra foi determinada por espectrofotometria nos comprimentos de onda de 260nm (correspondente ao pico de absorção de RNA) e $280 \mathrm{~nm}$ (correspondente ao pico de absorção de proteínas).

Os níveis de transcritos das citocinas investigadas foram determinados por PCR em tempo real, utilizando termociclador Applied Biosystems StepOne ${ }^{\mathrm{TM}}$, com primers específicos para cada gene. Os resultados expressos pelo método 2- $\Delta \Delta C T$ (Livak et al., 2001; Pfaffl et al., 2001), usando o gene housekeeping gliceraldeído 3-fosfato desidrogenase (GAPDH), conforme descrito por Toyoda et al., 2009.

A reação de PCR em tempo real foi realizada utilizando o kit SuperScript ${ }^{\mathrm{TM}}$ III Platinum ${ }^{\circledR S U B R}{ }^{\circledR}$ Green One-Step (Invitrogen Life Science, USA). Cada reação foi realizada com $15 \mu \mathrm{l}$, contendo $1,45 \mu \mathrm{l}$ de água deionizada estéril; 7,5 $\mu \mathrm{l}$ de 2x SYBR Green Reaction Mix (Invitrogen); 0,3 $\mu \mathrm{l}$ 
Métodos

de cada primer a 10nM; 0,3 $\mu$ l de SuperScript III RT/Platinum Taq Mix a 10pmol/ $\mu \mathrm{l} ; 0,15 \mu \mathrm{l}$ de ROX Reference Dye e $5 \mu \mathrm{l}$ de amostra (100ng de RNAm diluído em água DEPC). Todas as reações foram acompanhadas de controle negativo (todos os componentes da reação, exceto a amostra).

No Quadro a seguir encontram-se as sequências dos primers e condições de cada reação.

Quadro 1: Sequências de primers para a PCR.

\begin{tabular}{|l|l|l|l|}
\hline Gene & primer & anneling & $\begin{array}{l}\text { Gene } \\
\text { accession }\end{array}$ \\
\hline IL-10 & $\begin{array}{l}\text { 5'-CAGGGCTCCTGAAAGAGTTA-3' } \\
\text { 5'-AGAATGAGGTCAGGGGAATC-3' }\end{array}$ & L37781 \\
\hline IL-6 & $\begin{array}{l}\text { 5'-ATGGCTGAAGTCCAAGACC-3' } \\
\text { 5'-GGAATGTCCTCAGCTTGGTA-3' }\end{array}$ & AB164706 \\
\hline TNFa & $\begin{array}{l}\text { 5'-GCCCCACCTCGTGCTCCTCAC-3' } \\
\text { GGCAGGGGCTCTTGATGGCAGACA } \\
\text { G-3' }\end{array}$ & $\begin{array}{l}\text { AB177841 } \\
\text { GAPD } \\
\text { HACGGCACAGTCAAGGCTGAGAAC } \\
\text { G-3' } \\
\text { 5'- } \\
\text { CAACATACTCGGCACCGGCATCG-3' }\end{array}$ & AB040445 \\
\hline
\end{tabular}


Métodos

Foram coletadas as citocinas nos tempos de 2 e 4 horas após a aplicação de LPS. As citocinas analisadas foram a TNF-a, II-6 e IL-10. Esse protocolo foi escolhido com base na experiência do grupo de estudo do laboratório de Emergências Clínicas, que em trabalhos anteriores encontraram o pico das citocinas em questão após o período de 2 e 4 horas em ratos Wistar(Barbeiro, et al., 2010; Melo et al., 2010).

A análise dessas citocinas não foi realizada no mesmo animal em que houve a coleta do PEATE, pois devido à quantidade necessária de sangue para esse tipo de análise, o gerbil, por ser um animal pequeno, não resistiria aos procedimentos posteriores, inviabilizando a coleta do PEATE, principalmente naqueles que já estavam debilitados (grupos isquêmicos e sépticos). Porém, os mesmos procedimentos cirúrgicos de tempo e injeção de substância foram realizados da mesma maneira daqueles que foram submetidos à coleta do PEATE.

\subsection{Método Estatístico}

Para esse estudo os valores da onda V do PEATE foram comparados entre os grupos estudados - análise intergrupos- com o objetivo de verificar as diferenças entre cada grupo nas diferentes situações de coleta. Para essa análise, utilizaram-se os testes ANOVA e Tukey (Field, 2009). 
Métodos

Também foram comparados os valores da onda $V$ no mesmo animal de cada grupo -análise intragrupos- nas diferentes situações de coleta. Para essa análise foi utilizado o teste de Friedman (Bussab e Morettin, 2002).

E para avaliar os níveis de citocinas e compará-los entre os grupos foram utilizados os testes ANOVA e Tukey (Field, 2009).

Diferenças inferiores a $0,05 \quad(p<0,05)$ foram consideradas significantes. 
Resultados 
Resultados

\section{Resultados}

Neste capítulo serão apresentados os resultados obtidos na análise das citocinas no decorrer da sepse, e os valores de latência da onda $V$ do PEATE nos grupos estudados em todos os momentos de coleta em uma análise intra e intergrupos.

Para facilitar a explanação, os resultados serão divididos em três dois tópicos:

$\checkmark$ análise das citocinas;

$\checkmark$ análise da latência da onda $\vee$ do PEATE, em relação a sepse e isquemia;

$\checkmark$ análise da latência da onda $V$ do PEATE, em relação a influência do anestésico.

5.1. Análise das citocinas - caracterização dos grupos estudados

As Tabelas e Gráficos que seguem mostram os resultados encontrados no sangue dos animais dos diferentes grupos estudados, nas diferentes horas após os procedimentos realizados.

Foram analisadas as citocinas IL-6, TNF- $\alpha$ e IL-10 nos intervalos de 2 e 4 horas. 
Resultados

Gráfico IL-6 (n=54)

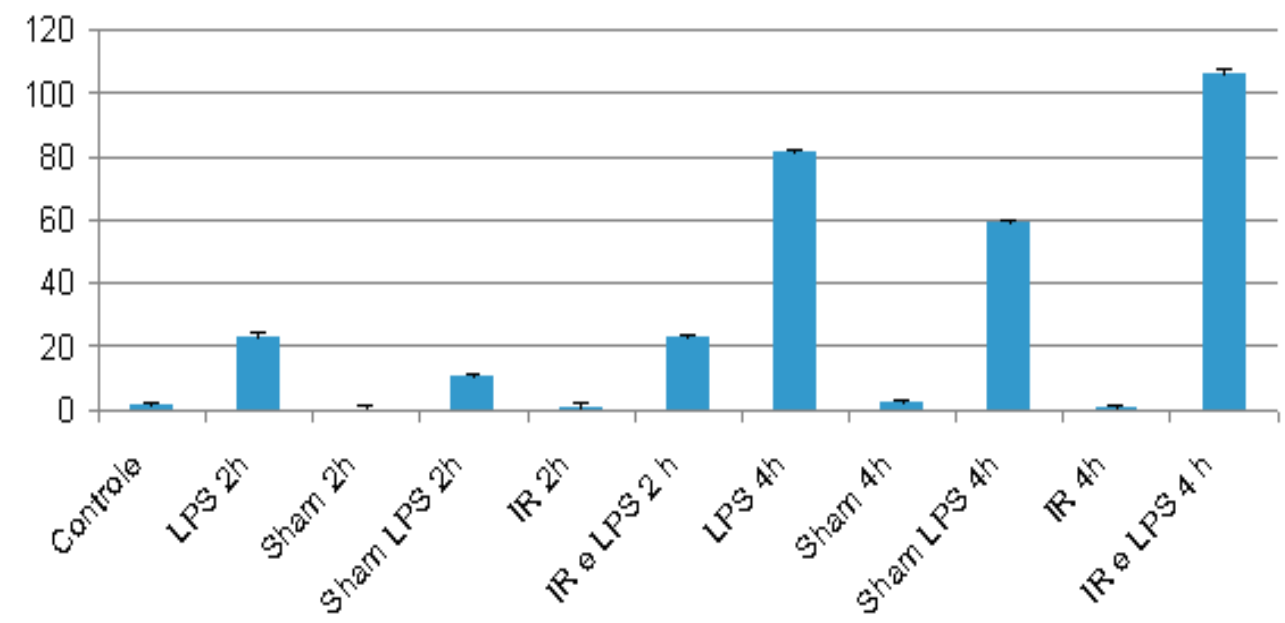

Gráfico 1: Nível da citocina IL-6 nos diferentes grupos estudados. $\mathrm{IR}=$ grupo isquêmico

Tabela 1: Valores da citocina IL-6 entre os grupos estudados.

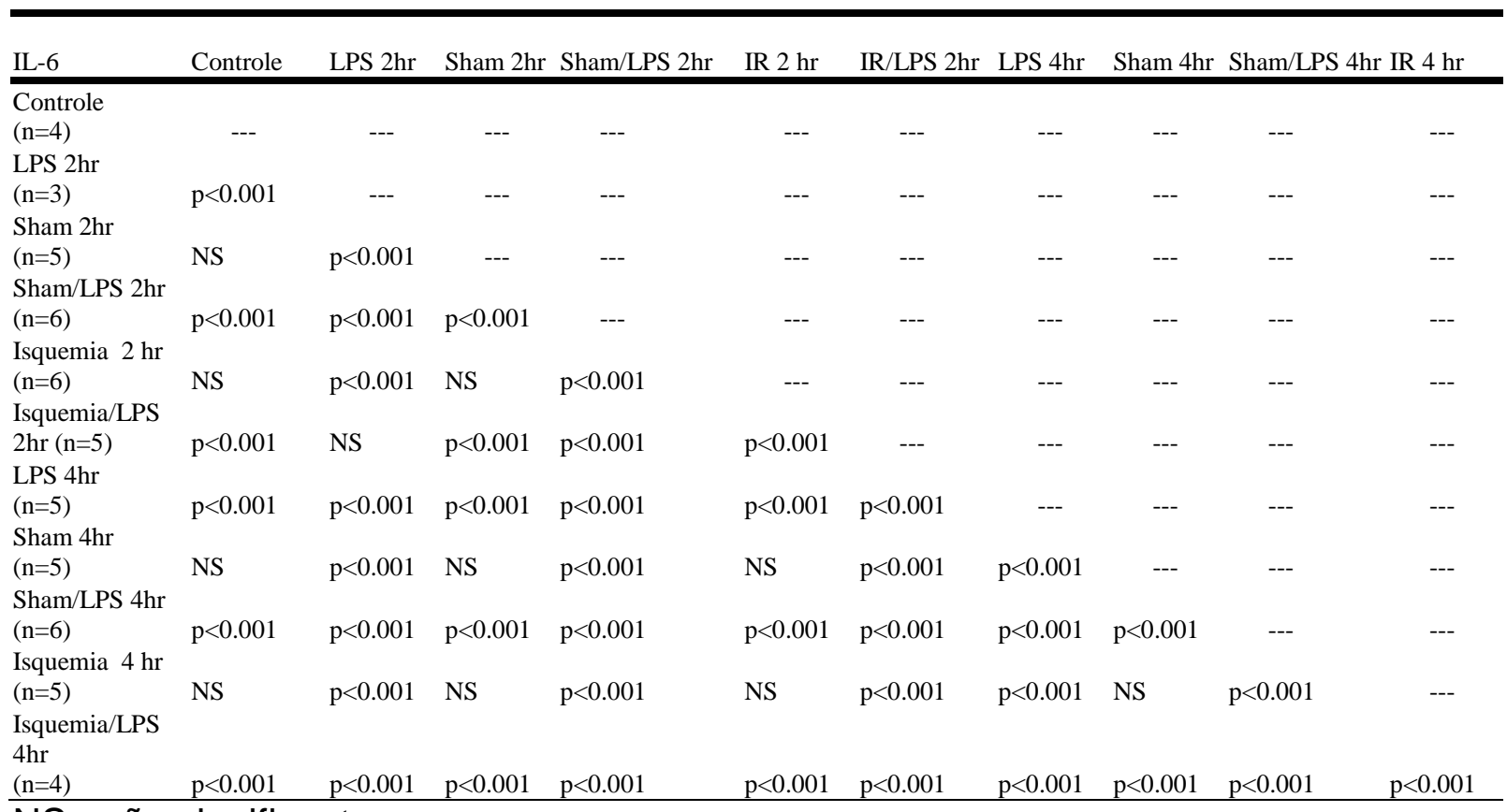

$\mathrm{NS}=$ não significante

$\mathrm{N}=$ número de animais

$I R=$ grupo isquêmico 
Resultados

Observa-se no Gráfico 1 o aumento da citocina IL-6 principalmente nos seguintes grupos : LPS, Sham/LPS, Isquemia/LPS - 2 e 4 horas. Sendo observado um aumento significativo (Tabela 1) entre a segunda e quarta hora após a aplicação de LPS. Observa-se um pico dessa citocina no período de 4 horas. Não foi observada diferença significante entre os grupos controle, isquemia e sham.

Gráfico TNF $-\alpha(n=58)$

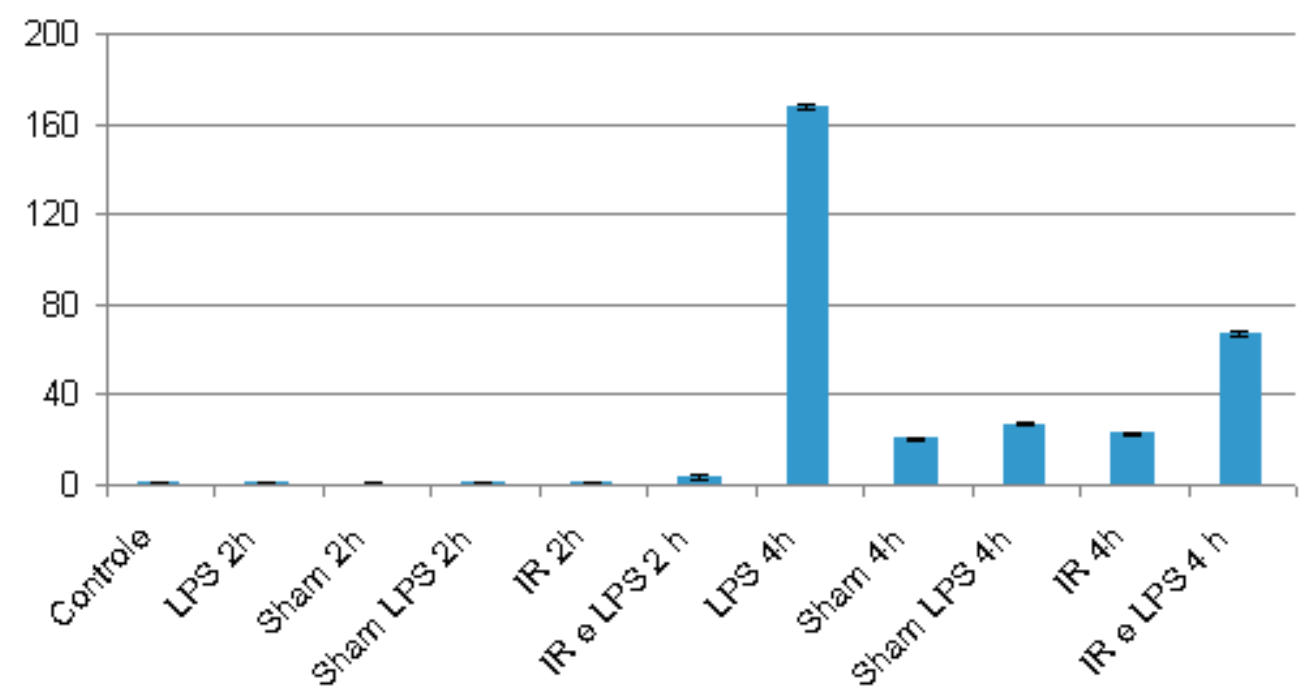

Gráfico 2: Nível da citocina TNF - a nos diferentes grupos estudados.

$\mathrm{IR}=$ grupo isquêmico 
Resultados

Tabela 2: Valores da citocina TNF- $\alpha$ entre os grupos estudados.

\begin{tabular}{|c|c|c|c|c|c|c|c|c|c|c|}
\hline TNF & Controle & LPS $2 \mathrm{hr}$ & Sham $2 \mathrm{hr}$ & Sham/LPS & $2 \mathrm{hr}$ IR $2 \mathrm{hr}$ & IR/LPS $2 \mathrm{hr}$ & LPS $4 \mathrm{hr}$ & Sham $4 \mathrm{hr}$ & Sham/LPS $4 \mathrm{hr}$ & IR $4 \mathrm{hr}$ \\
\hline $\begin{array}{l}\text { Controle } \\
(\mathrm{n}=4)\end{array}$ & --- & --- & --- & --- & --- & --- & --- & --- & --- & --- \\
\hline $\begin{array}{l}\text { LPS } 2 \mathrm{hr} \\
(\mathrm{n}=3)\end{array}$ & NS & --- & --- & --- & --- & --- & --- & --- & --- & --- \\
\hline $\begin{array}{l}\text { Sham } 2 h r \\
(n=6)\end{array}$ & NS & NS & --- & --- & --- & --- & --- & --- & --- & --- \\
\hline $\begin{array}{l}\text { Sham/LPS } 2 \mathrm{hr} \\
(\mathrm{n}=6)\end{array}$ & NS & NS & NS & --- & --- & --- & --- & --- & --- & --- \\
\hline $\begin{array}{l}\text { Isquemia } 2 \mathrm{hr} \\
(\mathrm{n}=6)\end{array}$ & NS & NS & NS & NS & --- & --- & --- & --- & --- & --- \\
\hline $\begin{array}{l}\text { Isquemia/LPS } \\
2 \mathrm{hr}(\mathrm{n}=6)\end{array}$ & NS & NS & $\mathrm{p}<0.05$ & NS & NS & --- & --- & --- & --- & --- \\
\hline $\begin{array}{l}\text { LPS 4hr } \\
(\mathrm{n}=5)\end{array}$ & $\mathrm{p}<0.001$ & $\mathrm{p}<0.001$ & $\mathrm{p}<0.001$ & $\mathrm{p}<0.001$ & $\mathrm{p}<0.001$ & $\mathrm{p}<0.001$ & --- & --- & --- & --- \\
\hline $\begin{array}{l}\text { Sham } 4 \mathrm{hr} \\
(\mathrm{n}=6)\end{array}$ & $\mathrm{p}<0.001$ & $\mathrm{p}<0.001$ & $\mathrm{p}<0.001$ & $\mathrm{p}<0.001$ & $\mathrm{p}<0.001$ & $\mathrm{p}<0.001$ & $\mathrm{p}<0.001$ & --- & --- & --- \\
\hline $\begin{array}{l}\text { Sham/LPS } 4 \mathrm{hr} \\
(\mathrm{n}=6)\end{array}$ & $\mathrm{p}<0.001$ & $\mathrm{p}<0.001$ & $\mathrm{p}<0.001$ & $\mathrm{p}<0.001$ & $\mathrm{p}<0.001$ & $\mathrm{p}<0.001$ & $\mathrm{p}<0.001$ & $\mathrm{p}<0.01$ & --- & --- \\
\hline $\begin{array}{l}\text { Isquemia } 4 \mathrm{hr} \\
(\mathrm{n}=6)\end{array}$ & $\mathrm{p}<0.001$ & $\mathrm{p}<0.001$ & $\mathrm{p}<0.001$ & $\mathrm{p}<0.001$ & $\mathrm{p}<0.001$ & $\mathrm{p}<0.001$ & $\mathrm{p}<0.001$ & NS & $\mathrm{p}<0.01$ & --- \\
\hline $\begin{array}{l}\text { Isquemia /LPS } \\
4 \mathrm{hr}(\mathrm{n}=4)\end{array}$ & $\mathrm{p}<0.001$ & $\mathrm{p}<0.001$ & $\mathrm{p}<0.001$ & $p<0.001$ & $\mathrm{p}<0.001$ & $\mathrm{p}<0.001$ & $\mathrm{p}<0.001$ & $\mathrm{p}<0.001$ & $\mathrm{p}<0.001$ & $\mathrm{p}<0.001$ \\
\hline
\end{tabular}

O Gráfico 2 que corresponde ao nível de TNF-a possui grande pico no grupo LPS-4 horas, com valor de significância entre todos os outros grupos. Observa-se também aumento do nível dessa citocina em todos os demais grupos após 4 horas, mesmo aqueles sem aplicação de LPS (sham e isquêmico), com valores significantes entre os grupos de 2 e 4 horas, conforme mostra a Tabela 2. 
Resultados

Gráfico IL-10 (N=53)

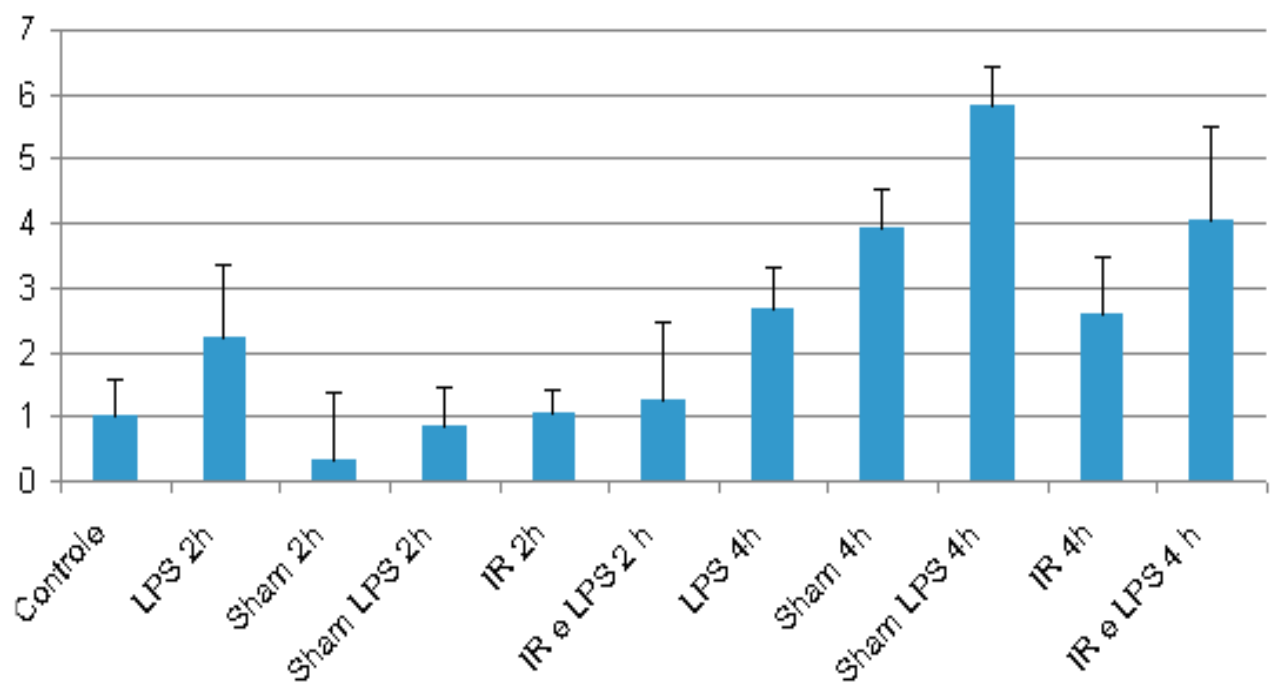

Gráfico 3: Nível da citocina IL-10 nos diferentes grupos estudados $\mathrm{IR}=$ grupo isquêmico

Tabela 3: Valores da citocina IL-10 entre os grupos estudados.

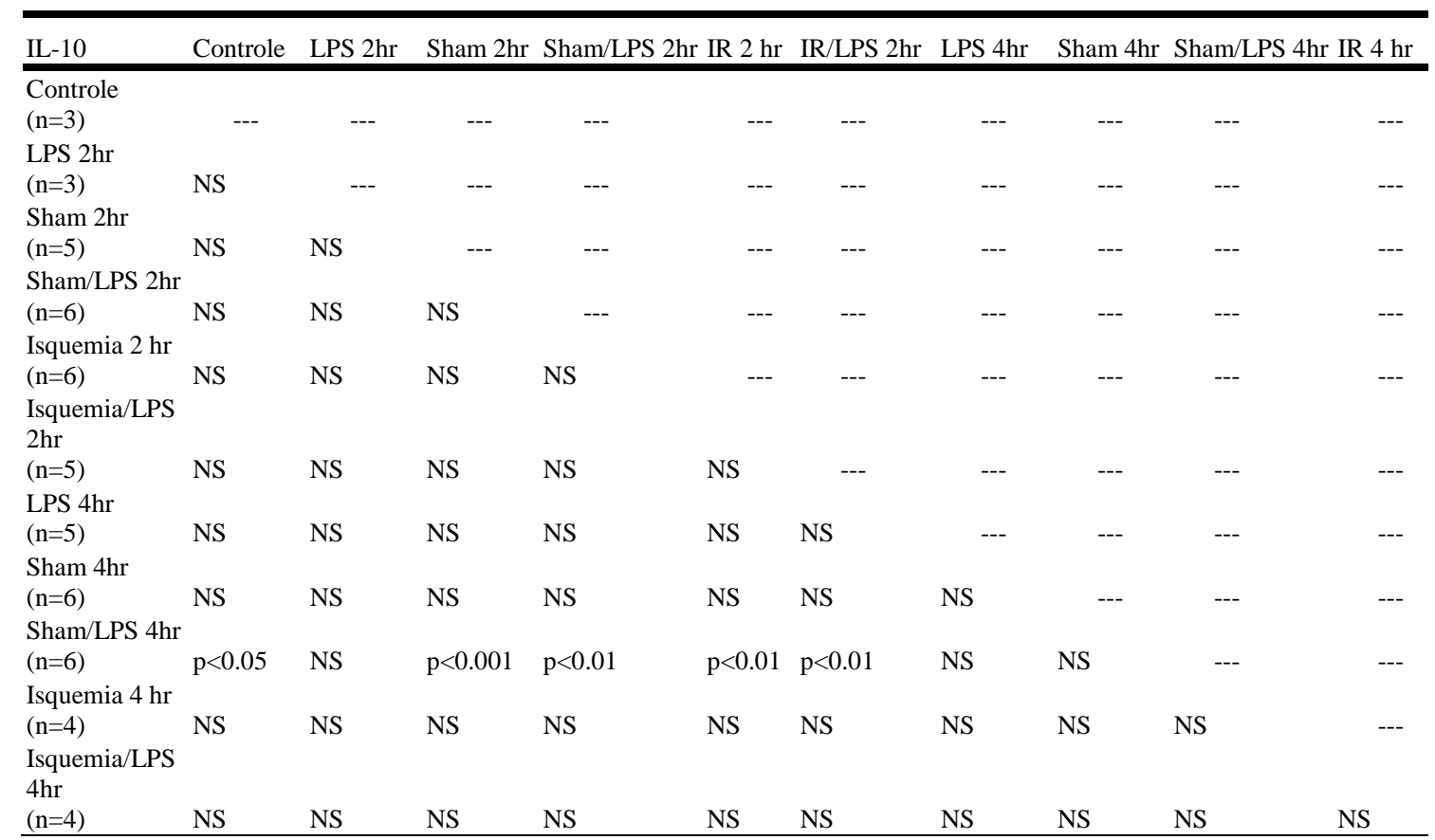

$\mathrm{NS}=$ não significante

$\mathrm{N}=$ número de animais

$\mathrm{IR}=$ grupo isquêmico 
Resultados

Já na análise do nível de IL-10, uma citocina anti-inflamatória, observa-se diferença estatisticamente significante entre o grupo sham/LPS 4horas e os grupos controle, sham 2 horas, sham/LPS 2 horas, isquemia 2 horas, isquemia/LPS 2 horas que pode ser visto na Tabela 3.

\subsection{Análise do PEATE}

O presente estudo utilizou 72 gerbils, sendo que cada grupo teve um total de doze animais.

A Tabela 4 mostra média e desvio padrão das latências do PEATE por grupo em todos os momentos do estudo. É possível observar uma diferença nos valores da primeira coleta (pré) e última coleta $(E)$ em todos os grupos que foram submetidos à sepse (sepse,sham com sepse e isquemia com sepse). Observa-se o contrário nos grupos que não foram submetidos à sepse (controle, isquemia e sham). 
Resultados

Tabela 4: Média e desvio padrão (DP) das latências da onda $V$ do PEATE por grupo em todos os momentos do estudo, e $\mathrm{N}$ correspondente.

\begin{tabular}{lllllll}
\hline COLETA & CONTROLE & SEPSE & ISQUEMIA & SHAM & ISQUEMIA/ & SEPSE/SHAM \\
& $(\mathrm{N}=12)$ & $(\mathrm{N}=12)$ & $(\mathrm{N}=12)$ & $(\mathrm{N}=12)$ & SEPSE & $(\mathrm{N}=12)$ \\
& & & & & $(\mathrm{N}=12)$ & \\
\hline PRE & $3,03 \pm 0,18$ & $3,03 \pm 0,20$ & $2,99 \pm 0,12$ & $2,99 \pm 0,23$ & $3,03 \pm 0,18$ & $3,01 \pm 0,19$ \\
A & $3,00 \pm 0,13$ & $3,08 \pm 0,19$ & $3,04 \pm 0,16$ & $2,97 \pm 0,15$ & $3,15 \pm 0,33$ & $3,07 \pm 0,14$ \\
B & $3,45 \pm 0,50$ & $3,69 \pm 0,45$ & $3,30 \pm 0,19$ & $3,40 \pm 0,38$ & $3,55 \pm 0,40$ & $3,64 \pm 0,57$ \\
C & $3,95 \pm 0,61$ & $4,22 \pm 0,52$ & $3,75 \pm 0,62$ & $4,10 \pm 0,61$ & $4,01 \pm 0,56$ & $4,07 \pm 0,86$ \\
D & $3,63 \pm 0,55$ & $3,75 \pm 0,41$ & $3,41 \pm 0,54$ & $3,97 \pm 0,53$ & $4,00 \pm 0,67$ & $4,20 \pm 0,72$ \\
E & $2,98 \pm 0,23$ & $3,99 \pm 1,03$ & $3,02 \pm 0,21$ & $3,10 \pm 0,30$ & $4,42 \pm 0,93$ & $4,52 \pm 0,61$ \\
\hline
\end{tabular}

Abaixo encontram-se os Gráficos correspondentes a cada valor de latência da onda $\mathrm{V}$ nos diferentes momentos de coleta. 
Resultados

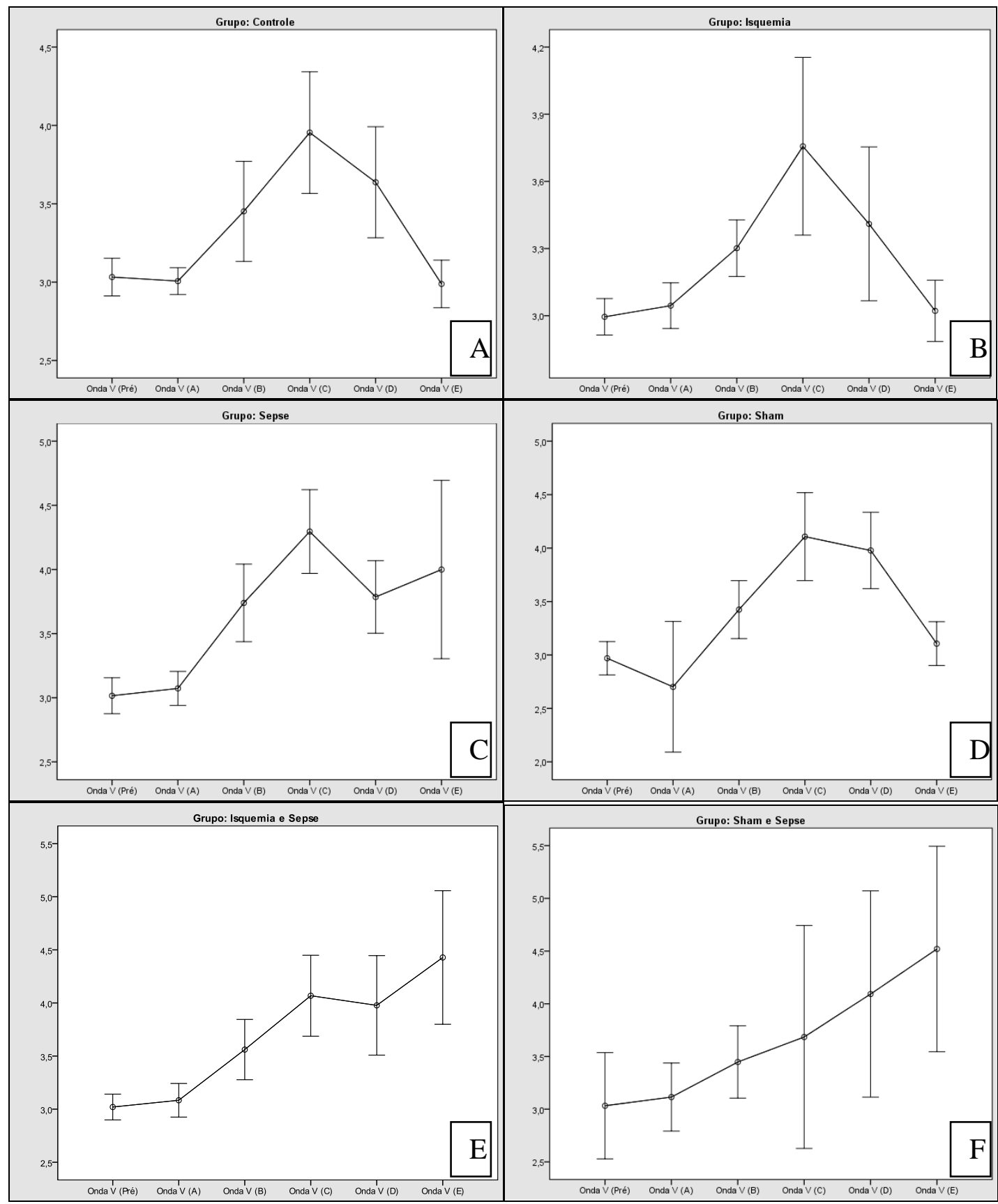

Gráfico 4: Média da latência da onda V do PEATE nas diferentes situações

de estudo dos grupos: Controle (A), Isquemia (B), Sepse (C), Sham (D), Isquemia e Sepse (E) e Sham e Sepse (F).

Foi realizada a média geral, obtida pelo método "Grand-Averaged" , de cada onda coletada do PEATE de todos os grupos nos diferentes 
Resultados

momentos de coleta (pré, A, B, C, D e E) e o resultado pode ser visto na Figura 5.

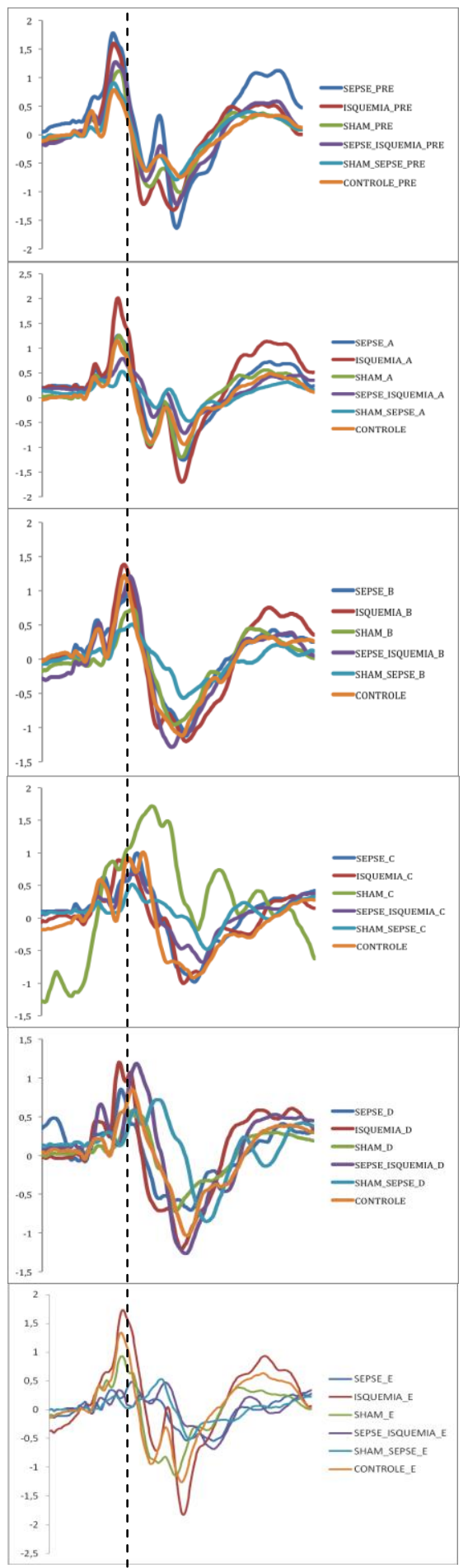

Figura 5: Traçado da média dó PEATE em cada grupo estudo em todos os momentos de coleta (pré, A, B, C, D e E). 
Resultados

5.2A. Análise da latência da onda $V$ do PEATE em relação à sepse e isquemia.

Para a análise da latência da onda $\mathrm{V}$ do PEATE em relação à sepse e isquemia utilizou-se a análise intergrupos.

Análise Intergrupos:

Foram comparados todos os grupos em todas as situações de coleta. A Tabela 5 mostra as situações e grupos onde houve piora do PEATE. Pode-se observar diferença estatisticamente significante principalmente na situação E entre os grupos que possuíam LPS e os que não tinham. 
Resultados

Tabela 5: Comparação intergrupos das médias das latências das ondas $V$ do PEATE nas diferentes situações do estudo.

\begin{tabular}{|c|c|c|c|c|c|c|}
\hline & Pré & Coleta A & Coleta B & Coleta C & Coleta D & Coleta E \\
\hline $\begin{array}{l}\text { Sepse } x \\
\text { Isquemia }\end{array}$ & NS & NS & NS & NS & NS & .007 \\
\hline $\begin{array}{l}\text { Sepse } x \\
\text { Isquemia/sepse }\end{array}$ & NS & NS & NS & NS & NS & NS \\
\hline $\begin{array}{l}\text { Sepse } x \\
\text { Controle }\end{array}$ & NS & NS & NS & NS & NS & .005 \\
\hline Sepse $x$ sham & NS & NS & NS & NS & NS & .022 \\
\hline $\begin{array}{l}\text { Sepsex } \\
\text { sham/sepse }\end{array}$ & NS & NS & NS & NS & NS & NS \\
\hline $\begin{array}{l}\text { Isquemiax } \\
\text { isquemia/sepse }\end{array}$ & NS & NS & NS & NS & NS & .000 \\
\hline Isquemiax controle & NS & NS & NS & NS & NS & NS \\
\hline Isquemiax sham & NS & NS & NS & NS & NS & NS \\
\hline $\begin{array}{l}\text { Isquemiax } \\
\text { sham/sepse }\end{array}$ & NS & NS & NS & NS & .030 & .002 \\
\hline $\begin{array}{l}\text { Isquemia/sepse } x \\
\text { controle }\end{array}$ & NS & NS & NS & NS & NS & .000 \\
\hline $\begin{array}{l}\text { Isquemia/sepse } x \\
\text { sham }\end{array}$ & NS & NS & NS & NS & NS & .000 \\
\hline $\begin{array}{l}\text { Isquemia/sepse } x \\
\text { sham/sepse }\end{array}$ & NS & NS & NS & NS & NS & NS \\
\hline Controlex sham & NS & NS & NS & NS & NS & NS \\
\hline $\begin{array}{l}\text { Controlex } \\
\text { sham/sepse }\end{array}$ & NS & NS & NS & NS & NS & .002 \\
\hline $\begin{array}{l}\text { Shamx } \\
\text { sham/sepse }\end{array}$ & NS & NS & NS & NS & NS & .005 \\
\hline
\end{tabular}

NS: não significante 
Resultados

5.2B. Análise da latência da onda $V$ do PEATE em relação à influência do anestésico.

Para a análise da latência da onda $V$ do PEATE em relação à influência do anestésico utilizou-se a análise intragrupo.

Análise intragrupo:

Para a análise intragrupo foram apenas utilizados os animais que sobreviveram até a coleta E. Nessa análise é possível observar o efeito da anestesia em todos os grupos. Observa-se uma diferença significativa $(p \leq 0,05)$ da onda $V$ entre os momentos pré e $C$; pré e $D ; A$ e $C$; $A$ e $D$ na maioria dos grupos (com exceção do grupo sham/sepse). Essas coletas foram feitas no segundo dia, em que foi utilizado quatro doses de anestésico, ou seja, havia um acúmulo da substância ketamina no animal. Observa-se aumento, inclusive, no grupo controle.

É possível também observar os valores significativos nos grupos que possuem aplicação de LPS entre as ondas pré e ondas E, mostrando a piora individual dos animais desses grupos. (Tabela 6). 
Resultados

Tabela 6: Comparação intragrupos das médias das latências das ondas $V$ do PEATE nas diferentes situações de coleta.

\begin{tabular}{|c|c|c|c|c|c|c|}
\hline & $\begin{array}{l}\text { Sepse } \\
(N=11)\end{array}$ & $\begin{array}{l}\text { Isquemia } \\
(\mathrm{N}=12)\end{array}$ & $\begin{array}{l}\text { Sham } \\
(\mathrm{N}=11)\end{array}$ & $\begin{array}{l}\text { Sham/ } \\
\text { Sepse } \\
(\mathrm{N}=4)\end{array}$ & $\begin{array}{l}\text { Isquemia/ } \\
\text { Sepse } \\
(\mathrm{N}=11)\end{array}$ & $\begin{array}{l}\text { Controle } \\
(\mathrm{N}=12)\end{array}$ \\
\hline Pré X A & NS & NS & NS & NS & NS & NS \\
\hline Pré X B & .038 & NS & NS & NS & NS & NS \\
\hline Pré X C & .014 & .006 & .003 & NS & .003 & .000 \\
\hline Pré X D & .000 & NS & .003 & NS & .038 & .028 \\
\hline Pré X E & .046 & NS & NS & .037 & .001 & NS \\
\hline$A \times B$ & NS & NS & NS & NS & NS & NS \\
\hline$A \times C$ & .000 & .004 & .000 & NS & .014 & .000 \\
\hline$A \times D$ & .031 & NS & .000 & NS & NS & .007 \\
\hline$A \times E$ & NS & NS & NS & NS & .003 & NS \\
\hline$B \times C$ & NS & NS & NS & NS & NS & NS \\
\hline$B \times D$ & NS & NS & NS & NS & NS & NS \\
\hline$B \times E$ & NS & NS & NS & NS & NS & NS \\
\hline$C \times D$ & NS & NS & NS & NS & NS & NS \\
\hline$C \times E$ & NS & NS & .038 & NS & NS & .000 \\
\hline$D \times E$ & NS & NS & .038 & NS & NS & .005 \\
\hline
\end{tabular}

NS: não significante. 
Discussão

\section{Discussão}

A discussão será dividida em três tópicos de acordo com os objetivos propostos nesse trabalho.

6.1. Análise de Citocinas do Sangue dos Animais - Caracterização dos Grupos Estudados.

O objetivo dessa análise foi caracterizar os grupos estudados, demonstrando a inflamação por meio do nível de citocinas IL-6, TNF-a e IL10 presentes em cada grupo.

Em relação à citocina IL-6, no Gráfico 1, observa-se um nível dessa citocina maior nos grupos com sepse 2 e 4 horas após a injeção do LPS. Essa citocina é liberada no desenvolvimento da sepse e possui caráter inflamatório (Opal e DePalo, 1999). Se compararmos os grupos com sepse com os demais que não receberam a aplicação de LPS, veremos uma diferença estatisticamente significante entre eles. O mesmo ocorre entre os grupos de 2 e 4 horas com sepse, demonstrando que essa citocina aumenta no decorrer do tempo, no desenvolvimento da inflamação. Esse achado é compatível com dados encontrados na literatura (Melo, 2010) e caracterizam, dessa forma, os grupos que estão inflamados, ou seja, aqueles que receberam a aplicação de LPS.

O LPS presente na superfície celular das bactérias gram-negativas provoca o reconhecimento do sistema imune inato (Fock, 2005), e a partir 
Discussão

disso inicia-se um processo inflamatório no organismo do animal, e através de eventos em cascata, com aumento da produção de moléculas inflamatórias, ocorre o quadro de sepse (Baldwin Jr., 2001). Especificamente, a produção da interleucina IL-6 está presente na fase aguda da inflamação e promove a liberação de células B e secreção de Ac, promovendo, dessa forma, uma potencialização do processo inflamatório (Opal e DePalo, 1999). Nesse estudo a indução da sepse foi feita através da aplicação intraperitoneal da substância de LPS no gerbil.

Já no Gráfico 2 observa-se o nível de TNF-a. É possível observar um aumento dessa citocina após 4 horas, tanto nos grupos que receberam a aplicação de LPS como nos que não receberam, mas que passaram por procedimento cirúrgico (sham/isquemia). O aumento dessa citocina está presente em situações cirúrgicas, como resposta do organismo afetado (Funes, 2005), e durante a sepse é a primeira citocina liberada. O TNF- $\alpha$ possui papel importante no desenvolvimento da inflamação e está relacionado aos quadros de hipotensão, aumento da permeabilidade vascular, anorexia, dano à mucosa intestinal, hiperglicemia e ação direta no hipotálamo (Bilate, 2007).

Os grupos LPS/Sham e LPS/ Isquêmico demonstram um nível menor de TNF- $\alpha$ em relação ao grupo de LPS- 4 horas. Nesses animais que sofreram a isquemia cerebral ou apenas a cirurgia previamente, sem o clampeamento da carótida, houve o desencadeamento da inflamação causado pelo próprio procedimento cirúrgico, e quando foi injetado LPS posteriormente, as células imunológicas responderam com menor produção 
Discussão

de citocinas. Tal fato pode ser entendido como um mecanismo de précondicionamento, já demonstrado em pesquisa em casos de infarto do miocárdio e isquemia hepática no transplante (Chiu et al., 2003; Breivik et al., 2011), que consiste na indução de breves períodos de isquemia seguidos de reperfusão, para tornar o órgão mais resistente a períodos mais longos de isquemia (Lima et al., 2000). No caso do presente estudo, o processo isquêmico e/ou cirúrgico parece ter deixado o animal menos vulnerável ao processo séptico.

Os achados expostos no Gráfico 3 demonstram os valores da citocina IL-10. Observa-se diferença entre o grupo Sham/LPS 4 horas em relação aos demais de 2 horas e controle. Verifica-se também uma diferença não estatisticamente significante entre os grupos de 4 horas. A IL-10 é uma citocina anti-inflamatória, dessa maneira o aumento do seu nível com o decorrer do tempo significa a tentativa do organismo em "corrigir" a resposta do organismo, tanto nas situações cirúrgicas (grupos sham e isquemia) quanto após a aplicação de LPS. Além disso, no decorrer da sepse pode haver também um aumento exacerbado de citocinas anti-inflamatórias, promovendo a presença de infecções secundárias, caracterizando o quadro de síndrome da resposta anti-inflamatória compensatória e piorando as condições clínicas do indivíduo (Holub, 2007). Nesse estudo não acompanhamos a evolução do quadro séptico. Os animais foram sacrificados no terceiro dia, após a última coleta.

Dessa forma, conseguimos demonstrar histologicamente a inflamação do grupo de animais que receberam a aplicação de LPS, bem 
Discussão

como o desenvolvimento dos níveis de citocinas ao longo da doença no gerbil, caracterizando os grupos avaliados neste estudo.

\subsection{Análise Intergrupo do PEATE - Influência da Sepse e Isquemia}

O objetivo dessa análise foi avaliar os valores de latência do PEATE nos grupos shams, isquêmicos, sépticos e controle antes e após cada procedimento, visando observar a relação dos valores do PEATE com as respectivas situações em que os gerbils foram submetidos.

O modelo utilizado nesse estudo, o gerbil (Meriones unguiculatus), possui faixa de audibilidade entre 1 e $20 \mathrm{KHz}$ (Ryan, 1976), dessa maneira, a estimulação do PEATE com o clique mostrou-se viável para a avaliação da audição nesses animais. Além disso, Smiths e Kraus, 1987, relataram que a maturação de latências de ondas do PEATE em gerbils ocorre entre 25 e 40 dias após o nascimento. Nesse estudo, os animais tinham entre três e cinco meses de vida, portanto as respostas apresentadas não estavam relacionadas a nenhum processo maturacional.

Os dados das Tabelas 4 e 5 mostram os valores de onda $V$ do PEATE nos diferentes grupos estudados. Na coleta E, é possível perceber a diferença entre os grupos submetidos à sepse (sepse, isquemia/sepse, sepse/sham) daqueles não submetidos à sepse (sham, isquêmico e controle). Com isso observamos um aumento de latência da onda $V$ do PEATE no desenvolvimento da sepse (coleta E- 24horas após aplicação do 
Discussão

LPS), o que não se observa nos demais grupos avaliados e, também nos períodos de 2, 4 e 8 horas após a aplicação de LPS, já que não existe praticamente alteração significativa entre as coletas pré, $A, B, C$ e D dos grupos sépticos com os demais.

$\mathrm{Na}$ presença de infecção grave, pode haver alteração nas vias auditivas centrais. Como resultado desse evento, podemos observar um prolongamento de resposta do PEATE (Welkoborsky e Lowitzsch, 1992; Bankaitis, 1995). A sepse, que é uma doença de caráter inflamatório, pode acarretar um mau funcionamento cerebral, devido ao aumento de citocinas que podem provocar, inclusive, apoptose celular (Hotchkiss et al., 2002) e alteração da neurotransmissão sináptica (Silva, 2007b). Isso pode justificar aumento de resposta na latência do PEATE nos grupos avaliados nesse estudo, após 24 horas da aplicação de LPS. O exame de eletroencefalograma também pode mostrar-se alterado na presença dessa patologia (Young et al., 1990).

Dessa forma, o PEATE pode ser útil como um preditivo para avaliar as condições clínicas e servir como medidor de prognóstico evidenciando a melhora ou não do indivíduo. Com essa perspectiva o PEATE tem sido cada vez mais estudado no quadro do coma cerebral (Jardim et al., 2008), já que é um exame não invasivo, confiável e apresenta reprodutibilidade mesmo em um ambiente eletricamente carregado, como nas Unidades de Terapia Intensiva (Hall e Tucker, 1986). 
Discussão

Os trabalhos envolvendo sepse e PEATE são escassos na literatura. Até a presente data deste escrito (março/2012) não foi achado nenhum trabalho publicado envolvendo PEATE e sepse.

Por outro lado, os grupos submetidos apenas à isquemia (sem aplicação do LPS) não apresentaram diferença estatisticamente significante daqueles sem isquemia e sem sepse. O valor de latência absoluta da onda $\mathrm{V}$ não se alterou entre a coleta pré e coleta $E$. Os trabalhos na literatura também são escassos e variam quanto ao tempo e modo de oclusão de irrigação sanguínea cerebral o que pode influenciar nos resultados encontrados.

No trabalho em questão, os animais foram submetidos à oclusão da carótida no primeiro dia de experimento, e o PEATE foi coletado após 24 horas de tal procedimento. Foi analisado apenas o valor de latência da onda V.

Sohmer et al., 1984, avaliaram a onda I do PEATE em gatos submetidos à isquemia logo após a oclusão da carótida comum. Eles encontraram presença dessa onda e ausência das demais. No nosso estudo conseguimos avaliar a onda V do PEATE após 24 horas do procedimento isquêmico.

Cowen et al., 1987, submeteram gerbils também à oclusão de carótida seguida do processo de reperfusão, porém eles avaliaram outro tipo de potenciais evocados - os somatossensoriais que avaliam outra região anatômica. Após a oclusão, eles observaram diminuição de amplitude dos potenciais avaliados e aumento da condução de tempo. Já no processo de 
Discussão

reperfusão foi observada uma diferença estatisticamente significante de resposta após 4 horas, com aumento de amplitude nos potenciais somatossensoriais. Analisando também os potenciais somatossensoriais, Zauner et al., 2002, avaliaram pacientes com sepse severa e choque séptico. Eles encontraram alteração nesses potenciais e o prejuízo dos mesmos esteve associado à severidade da doença.

Tanto o estudo de Cowen et al., 1987, como o de Zauner et al., 2002, podem justificar os valores do PEATE mantidos antes e após a isquemia nesse estudo. O PEATE avalia a região de tronco encefálico, sabe-se que danos isquêmicos estão relacionados, principalmente, às regiões corticais (O’Sullivan, 1993), sendo que a área CA1 do hipocampo é a mais vulnerável a lesões isquêmicas, observando-se perda de neurônios nessa região (Kirino, 1982). Nos estudos realizados pelos autores com os potenciais somatossensoriais, os registros ocorrem em áreas mais centrais, que são mais atingidas nos quadros isquêmicos. $\mathrm{Em}$ trabalho realizado anteriormente, Moreira 2008, utilizou o potencial evocado auditivo de longa latência, o Mismatch Negativity, para avaliar lesões isquêmicas em gerbils submetidos a diferentes temperaturas após a lesão provocada.

Inui et al., 1995, coletaram o PEATE em ratos submetidos à oclusão da artéria cerebelar ântero-inferior, porém em tempos muito menores do que os nossos $(0,6,15,30$ e 60 minutos após a oclusão), eles observaram um resultado heterogêneo, com diferentes respostas de latências do PEATE. Eles justificaram tal fato com a provável taxa de irrigação sanguínea na cóclea. No presente estudo, houve a oclusão das carótidas que no modelo 
Discussão

experimental utilizado é a única forma de irrigação cerebral, já que o gerbil não possui o Polígono de Willis, que é um conjunto de artérias que irrigam o cérebro (Levine e Shon, 1969). A primeira coleta do PEATE foi realizada após 24 horas da oclusão, dessa maneira, pode ter ocorrido alguma lesão na irrigação sanguínea, porém o próprio organismo pode ter se recuperado do evento. Dessa maneira, quando se registrou o PEATE nada se mostrou alterado nos grupos submetidos à isquemia

A conclusão da análise entre os grupos estudados é de que o PEATE se mostrou sensível ao grupo de gerbils submetidos à sepse, demonstrando um aumento da latência absoluta da onda V. O mesmo não ocorreu nos grupos submetidos à isquemia, cujo valor de onda V não se alterou.

6.3. Análise Intragrupo do PEATE - Influência do Anestésico.

O objetivo dessa análise foi verificar a influência do anestésico na resposta do PEATE.

Primeiramente todos os animais foram avaliados antes de qualquer procedimento. Tal medida (coleta pré) serviu como base para as análises subsequentes.

Como pode se observar na Figura 4, no segundo dia de experimento, todos os animais tinham seus PEATEs colhidos em quatro momentos (coletas A, B, C e D). De acordo com os dados das Tabelas 4 e 6, e Gráfico 4, observa-se um aumento significante da onda $V$ do PEATE entre as 
coletas pré e C, pré e $D, A$ e $C, A$ e $D$ (exceto grupo sham/sepse), o que nos revela uma influência do anestésico ketamina associado à xilazina na resposta do PEATE, uma vez que podemos ver esse aumento inclusive no grupo controle.

É importante ressaltar que para essa análise só foram considerados os animais que sobreviveram até a coleta E. No grupo sham/sepse o "n" ao final estava reduzido $(n=4)$, pois ao longo do estudo os animais desse grupo morreram. Isso pode ter influenciado na análise estatística e explicar a exceção desse grupo na diferença estatisticamente significante entre as coletas pré e C; A e C nessa análise.

É possível observar também que no terceiro dia de coleta (coleta E) a média dos valores de latência da onda $V$ no grupo controle se mostra muito próximo daquele da coleta inicial (coleta pré), confirmando ainda mais a influência da droga administrada. Os valores encontrados nas coletas B e C, que se mostram aumentados progressivamente, devem-se ao fato da aplicação seguida de anestésico (2 horas), portanto, na coleta C havia uma concentração aumentada de ketamina/xilazina no organismo do animal avaliado. Na coleta $\mathrm{D}$ (8 horas), observa-se uma discreta diminuição de valor, embora sem diferença estatisticamente significante, devido à provável eliminação do anestésico no organismo dos gerbils.

Tal achado vai ao encontro de outros estudos que utilizaram o mesmo tipo de combinação de anestésico e encontraram aumento de respostas no PEATE em gatos e ratos. Sims e Horohov, 1986, relataram aumento da latência da onda $V$ após $5,10,25$ e 35 minutos da injeção de dose de 
Discussão

ketamina $(10 \mathrm{mg} / \mathrm{kg})$ e xilazina $(11 \mathrm{mg} / \mathrm{kg})$ em gatos. Smith e Mills,1988, observaram discreto aumento da onda P6 (VI) e aumento de amplitude das ondas P4 (IV) e P6 (VI) em gerbils adultos submetidos ao mesmo tipo de anestésico, com concentração de $50 \mathrm{mg} / \mathrm{kg}$ de Ketamina e $1 \mathrm{mg} / \mathrm{kg}$ de xilazina. Van Looij et al., 2004, também constataram aumento de latências absolutas e interpicos no PEATE em ratos sob anestesia de ketamina $(120 \mathrm{mg} / \mathrm{kg})$ e xilazina $(7.5 \mathrm{mg} / \mathrm{kg})$ quando comparados aos resultados do animal em situação de alerta (acordado) a 90dBnNA e, também, diferença na pesquisa de limiar entre os ratos com e sem anestesia. Os que estavam sob condição de anestesia apresentaram limiares maiores em relação aos que estavam acordados. Comparando com os estudos citados, mesmo com a diferença entre a concentração das drogas administradas, houve uma compatibilidade com os nossos achados, evidenciando a influência do anestésico nos resultados do PEATE.

Em estudo recente, Norrix et al., 2012, observaram influência do anestésico sevoflurano nos valores de latências absolutas e interpicos do PEATE em crianças sob anestesia. Encontraram valores aumentados nesse grupo quando comparado a um grupo sem sedação e chamaram a atenção quanto à avaliação do PEATE sob o uso de anestesia.

Na prática clínica, o uso de anestésico para a realização do PEATE é realizado em centros cirúrgicos e hospitais. Pacientes difíceis de serem avaliados precisam ser sedados para o procedimento (Hall, 1992). Além disso, há o uso desse potencial no monitoramento cirúrgico, no qual o paciente encontra-se anestesiado e muitas vezes com quadro de hipotermia 
Discussão

(Rosenblum et al., 1985; Souza et al., 2003) e ainda em situações em que o paciente é avaliado após procedimento cirúrgico, ainda sob efeito de anestesia.

Esse prolongamento de onda do PEATE após uso de anestésico ketamina pode ser explicado através da farmacodinâmica dessa droga. Com o bloqueio de canal do receptor do tipo NMDA, ocorre uma diminuição da ação do glutamato e, portanto, uma diminuição na transmissão sináptica (Miyake et al., 1998). Além disso, a anestesia causa vasodilatação e diminui a temperatura corporal o que acarreta em uma diminuição na transmissão sináptica e provoca um aumento nas latências do PEATE (Stockard et al., 1978; Markand et al., 1987).

Portanto, os resultados dessa análise mostram o efeito do uso dos anestésicos ketamina associado à xilazina na latência da onda V do PEATE, revelando um aumento de resposta. É importante considerar a quantidade de droga administrada, ou seja, sucessivas doses em um curto espaço de tempo ou em situações de doses em grande quantidade em função de evento que necessite a sedação por mais tempo, como no caso de cirurgia.

Mais estudos precisam ser realizados a fim de investigar a influência do uso de anestésicos no PEATE em humanos. 
Conclusões 
Conclusões

\section{Conclusões}

Frente aos resultados obtidos nesse estudo, podemos concluir que:

$\checkmark$ O presente estudo encontrou forte correlação entre o aumento de latência da onda $V$ do PEATE nos animais submetidos à sepse. Dessa forma, a avaliação desse potencial pode servir como um fator de prognóstico para identificar prejuízo de tronco encefálico em gerbils com sepse.Em contrapartida, o mesmo não foi observado nos animais submetidos à isquemia;

$\checkmark$ Houve aumento dos níveis das citocinas IL-6, IL-10 e TNF- $\alpha$ nos animais que sofreram aplicação de LPS, revelando uma alteração de expressão gênica de moléculas pró (IL-6 e TNF-a) e anti-inflamatória (IL-10) no decorrer da sepse;

$\checkmark$ As latências da onda $V$ do PEATE foram alteradas quando comparadas antes e após o procedimento nos grupos sépticos, o que não ocorreu no grupo sham, controle e isquêmico;

$\checkmark$ O uso de Ketamina associada à xilazina influenciou o resultado do PEATE, aumentando o valor de latência absoluta da onda $\mathrm{V}$ do PEATE. Dessa forma, o clínico deve estar atento no uso dessa substância na avaliação do PEATE. 
Anexo

8. Anexo

Anexo A: Protocolo de aprovação pela CAPPesq

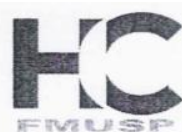

$N^{\circ}$ Protocolo: 0456/09

Título: MISMATCH NEGATIVITY EM GERBILS SUBMETIDOS À ISQUEMIA E SEPSE.

Pesquisador Responsável: Eliane Schochat

Pesquisador Executante: Janaina Patricio de Lima

Finalidade Acadêmica: Mestrado

Departamento: FISIOTERAPIA, FONOAUDIOLOGIA E TERAPIA OCUPACIONAL

○ Coordenador da Comissão de Ética para Análise de Projetos de Pesquisa - CAPPesq da Diretoria Clínica do Hospital das Clínicas da Faculdade de Medicina da Universidade de São Paulo, APROVOU / TOMOU CIÊNCIA adreferendum em 11/10/2011, do(s) documento(s) abaixo mencionado(s):

- Carta datada de 21/09/11 - Mudança de titulo de "Mismatch Negativity em gerbils submetidos à isquemia e sepse" para "Potencial Evocado Auditivo de Tronco Encefálico em gerbils submetidos a isquemia e sepse"

A CAPPesq em obediência à Resolução CNS 196/96, solicita ao pesquisador (a) s elaboração de relatório parcial e final.

No caso de relatório parcial é necessário informar o tempo previsto para a conclusão do protocolo e breve resumo dos resultados obtidos.
CAPPesq, 13 de Outubro de 2011

$$
\begin{aligned}
& \text { Qud-du Caxiso } \\
& \text { PROF. DR. EUCLIDES AYRES DE CASTILHO } \\
& \text { Coordenador } \\
& \text { Comissão de Ética para Análise de } \\
& \text { Projetos de Pesquisa - CAPPesq }
\end{aligned}
$$

Rua Dr. Ovídio Pires de Campos, 225 - Prédio da Administração - $5^{\circ}$ andar - CEP 05403-010 - São Paulo - SP. Fone: 5511 3069-6442 ramais 16,17,18 e 20 - e-mail: cappesq@hcnet.usp.br 
Referências Bibliográficas 


\section{Referências Bibliográficas}

Abdulkader RCRM. Utilizando bem os índices prognósticos. Rev Assoc Med Bras. 2003; 49(1): 2-2.

Abe ILM. Prevalência de acidente vascular cerebral em área de exclusão social na cidade de São Paulo, Brasil: utilizando questionário validado para sintomas [tese]. Faculdade de Medicina da Universidade de São Paulo. 2010.

Adams JC. Ascending projections to the inferior colliculus. J Comp Neurol. 1979; 183: 519-538.

Amadeo M, Shagass C. Brief Latency click-evoked potentials during waking and sleep in man. Psychophysiol. 1973;10: 244-250.

Aquilani R; Sessarego P; ladarola P; Barbieri A; Boschi F. Nutrition for brain recovery after ischemic stroke: na added value to rehabilitation. Nutr Clin Pract. 2011; 26 (3): 339- 345.

Baldwin Junior AS. The transcription factor NF-kB and human disease. J Clin Invest. 2001; 107 (1): 3-6.

Balém SA. Processamento auditivo central: aspectos temporais da audição e percepção acústica da fala. [Dissertação]. São Paulo: Pontifícia Universidade Católica de São Paulo; 1997.

Bankaitis AE. The effects of click rate on the auditory brain stem response $(A B R)$ in patients with varying degress of HIV-infection: a pilot study. Ear Hear. 1995; 16: 321-324.

Barbeiro DF, Barbeiro HV, Faintuch J, Ariga SK, Mariano M, Popi AF, 
de Souza HP, Velasco IT, Soriano FG. B-1cells temper endotoxemic inflammatory responses. Immunobiology. 2011; 216 (3): 302-308.

Basile-Filho A, Suen VMM, Martins MA, Coletto FA, Marson F. Monitorização da resposta orgânica ao trauma e à sepse. Medicina, Riberão Preto, 2001; 34: 5-17.

Bellis TJ. The science of central auditory processing. In: Assessment and management of central auditory processing disorders in the educational setting-from science to practice. Singular Publishing Group: San Diego, 1996.

Bilate AMB. Inflamação, citocinas, proteínas de fase aguda e implicações terapêuticas. Temas de Reumatologia Clínica. 2007; 8: 47-51.

Bobbin RP, May JG, Lemoine RL. Effects of pentobarbital and ketamine on brain stem auditory potentials. Arch Otolaryngol. 1979; 105: 467-470.

Booke M, Westphal M, Hinder F, Traber LD, Traber DL. Cerebral blood flow is not altered in sheep with Pseudomonas aeroginosa sepsis treated with norepineophrine or nitric oxide synthase inhibit. Anesth Analg. 2003; 96: 1122-1128.

Bowton DL, Bertels NH, Prough DS, Stump DA. Cerebral blood flow is reduced in patients with sepsis syndrome. Crit Care Med. 1989; 17: 399-403.

Breivik L, Helgeland E, Aarnes EK, Mrdalj J, Jonassen AK. Remote postconditioning by humoral factors in effluent from ischemic preconditioned rat hearts is mediated via PI3K/Akt-dependent cellsurvival signaling at reperfusion. Basic Res Cardiol. 2011; 106: 135145. 
Bussab WO, Morettin PA. Estatística básica. 5a edição. SP. Editora Saraiva, 2002.

Campos EBP; Yoshida WB. The role of free radicals in the pathophysiology of ischemia and reperfusion in stein flaps: experimental models and treatment strategies. J Vasc Br. 2004; 3 (4): 357-366.

Castro e Silva Júnior O; Centurion S; Pacheco EG; Brisotti JL; Oliveira AF; Dal Sasso K. Aspectos básicos da lesão de isquemia e reperfusão do pré-condicionamento isquêmico. Acta Cir Bras. 2002; 17: 96-100.

Chang RW; Jacobs S; Lee B. Predicting outcome among intensive care unit patients using computerized trend analysis of daily Apache II scores corrected for organ system failure. Intensive Care Med. 1998; 14:558-66.

Chiu JH, Tsou MT, Tung HH, Tai CH, Tsai SK, Chih CL, Lin JG, Wu $\mathrm{CW}$. Preconditioned somatothermal stimulation on median nerve territory increases myocardial heat shock protein 70 and protects rat hearts against ischemia - reperfusion injury. J Thorac Cardiovasc Surg. 2003; 125(3): 678-685.

Church MW, Gritzke R. Effects of ketamine anesthesia on the rat brainstem auditory evoked potential as a function of dose and stimulus intensity. Electroencephalogr Clin Neurophysiol. 1987; 67 (6): 570583.

Clausell N; Brauner JS. Mecanismos celulares e moleculares. In: Silva E; Friedman G. Sepse. São Paulo: Atheneu; 1999, págs.21-41.

Cohen J. The immunopathogenesis of sepsis. Nature. 2002; 420: 88591. 
Cohen MS, Britt RH. Effects of sodium pentobarbital, ketamine, halothane and chloralose on brainstem auditory evoked responses. Anesth Analg. 1982; 61: 338-343.

Cotran RS, Kumar V, Robbins SL. Robbins - Patologia Estrutural e Funcional. Rio de Janeiro:Guanabara-Koogan,2000.

Cowen DE, Combs DJ, Dempsey RJ. Measurement of somatosensory evoked potential in the Mogolian gerbil: the effects of cerebral ischaemia. Neurol Res. 1987; 9(3): 159-163.

Dantzer R, Konsman JP, Bluthe RM, Kelley KW. Neural and humoral pathways of communication from the immune system to the brain: parallel or convergent. Auton Neurosci. 2000; 85: 60-65.

Duarte SG; Campos AD; Colli BO. Functional evaluation of temporary focal cerebral ischemia: experimental model. Arq Neuropsiquiatr. 2003; 61(3B):751-6.

Faure PA, Fremouw T, Casseday JH, Covey E. Temporal masking reveals properties of sound-evoked inhibition in duration-tuned neurons of the inferior colliculus. J Neurosc. 2003; (23): 3052-3065.

Féres MCLC; Cairasco NG. Descrição anatômica da presença do íon zinco nos núcleos cocleares. Rev Bras Otorrinolaringol. 2003; 69 (2): 208-213.

Field H. Descobrindo a estatística usando o SPSS. $2 \alpha$ edição. SP. Editora Artmed, 2009.

Fock RA. Avaliação de aspectos da resposta inflamatória desencadeada pelo lipopolissacarídeo (LPS) em desnutrição protéica experimental. Quantificação dos receptores de LPS (CD14/TLR-4) e do fator de transcrição NFkB. [tese]. São Paulo: Universidade de São 
Paulo; 2005.

Funes HLX, Silva RCMA, Silva RF, Leite APM, Segantini FL, Calvi S. Comportamento do fator de necrose tumoral e da protein $C$ reativa em hepatectomia simultânea com colectomia em ratos. Rev Col Bras Cir. 2005; 32 (2): 94-99.

Goitein K, Fainmessser P, Sohmer H. Cerebral perfusion pressure and auditory brain-stem responses in childhood CNS disease. Am $J$ Dis Child. 1983; 137: 777-781.

Gorbunov FE; Penionzhkevich D; Kotenko EP. Application of peloidotherapy at the early stage of rehabilitation after cerebral ischemic stroke. Vopr Kurortol Fizioter Lech Fiz Kult. 2010 (1): 3-7.

Goss- Sampson MA, Kriss A. Effects of pentobarbital and ketaminexylazine anaesthesia on somatosensory, brainstem auditory and peripheral sensory -motor responses in the rat. Laboratory Animals. 1991; 25: 360-366.

Guyton AC. O sentido da audição. In: Tratado de Fisiologia Médica. Guanabara Koogan, 9a edição, São Paulo, 1997, pgs. 498506.

Hall JW, Tucker DA. Sensory evoked responses in the intensive care unit. Ear Hear. 1986; 7(4): 220-232.

Hall JW. Effect of stimulus factor. In: Handbook of auditory evoked responses. Massachusetts: Allyn and Bacon; 1992, págs. 104176.

Hashimoto I, Ishiyama Y, Yoshimoto T, Nemoto S. Brainstem auditory evoked potentials recorded directly from human brainstem and thalamus. Brain. 1981; 104: 841-859. 
Henkin CS; Coelho JC, Paganella MC, Siqueira RM, Dias FS. Sepse: uma visão atual. Scientia Medica. 2009; 19 (3): 135-145.

Holub M. Sepsis : infection and systemic inflammatory response. Cas Lek Cesk. 2007; 46: 109-114.

Hotchkiss RS, Tinsley KW, Swanson PE, Karl IE. Endothelial cell apoptosis in sepsis. Crit Care Med. 2002; 30: S225-S228.

Hyde ML. Frequency-specific BERA in infants. The journal of otolaryngology. 1985 (14): S19-S27.

Inui $\mathrm{H}$, Murai $\mathrm{T}$, Matsunaga $\mathrm{T}$. Auditory brainstem ischemia following selective occlusion of the anterior inferior cerebellar artery in the rat. Eur Arch Otorhinolaryngol. 1995; 252: 181-185.

Jardim, M; Person, OC; Rapoport, PB. Potencial evocado auditivo de tronco encefálico como auxilio diagnóstico de morte encefálica. PróFono Revista de Atualização Científica 2008, 20 (2): 123-128.

Jasper $\mathrm{HH}$. The ten twenty electrode system oh the international federation. Electroencephalogr Clin Neurophysiol. 1958; 10: 371-375.

Jewett DL; Romano HN; Wileiston JS. Human auditory evoked responses possible brain stem components selected on the scalp. Science. 1970 (167): 1517-1518.

Joaquim MAS; Patriota GC; Bianco AM. Isquemia encefálica, cascatas vasodilatadoras e alterações bioquímicas. Arq Bras Neurocir. 2010; 29 (2): 58-63.

Joris PX, Yin TC. Envelope coding in the lateral superior olive. I. Sensitivity to interaural time differences. J Neurophysiol. 1995; 73: 
1043-1062.

Juncal VR; Britto Neto LA; Camelier AA; Messeder OHC; Farias AMC. Impacto clínico do diagnóstico de sepse à admissão em UTI de um hospital privado em Salvador, Bahia. J Bras Pneumo. 2011; 37:85-92.

Kirino, T. Delayed neuronal death in the gerbil hippocampus following ischemia. Brain Research. 1982; 239(1):57-69.

Kortegen A; Hofmann G; Bauer, M. Sepsis: current aspects of pathophysiology and implication for diagnosis and treatment. Eur $J$ Trauma. 2006; 32: 3-9.

Krause GS; White BC; Aust SD; Nayini NR; Kumar K. Brain cell death following ischemia and reperfusion: a proposed biochemical sequence. Crit Care Med. 1988; 16: 714-726.

Lauffer H, Wenzel D. Brainstem acoustic evoked responses: maturacional aspects from cochlea to midbrain. Neuropediatrics. 1990;21: 59-61.

Lenzi GL, Frackowiak RSJ, Jones T. Cerebral oxygen metabolism and blood flowin human cerebral ischemic infarction. $J$ Cereb Blood Flow Metab. 1982; 2: 321-335.

Levine S; Shon D. Cerebral ischemia in infant and adult gerbils. Arch Path. 1969; 87: 315-317.

Lima JP, Alvarenga KF, Foelkel TP, Monteiro CZ, Agostinho RS. Os efeitos da polaridade do estímulo nos potenciais evocados auditivos de tronco encefálico. Rev Bras Otorrinolaringol. 2008; 74 (5): 725-730. 
Lima RS, Jordani MC, Souza MEJ, Picinato MANC, Franco CFF, Castro e Silva Jr O. Eficácia do pré-condiocionamento isquêmico na proteção das lesões de isquemia e reperfusão hepaticas. Acta Cir Bras. 2000; 15(2): 96-96.

Litovsky RY, Fligor BJ, Tramo MJ. Functional role of the human inferior colliculus in binaural hearing. Hear Res. 2002; 165: 177- 188.

Livak KJ, Schmittgen TD. Analysis of relative gene expression data using real-time quantitative PCR and the 2 (-Delta Delta $C(T)$ ) Method. Methods. 2001; 25 (4): 402-8.

Lomar FP. Manifestações Clínicas: caracterização inicial da doença. In: Silva FP, Velasco IT. Sepse. São Paulo: Manole. 2007, pags. 1927.

Markand ON, Lee Bl, Warren C, Stoelting RK, King RD, Brown JW, Mahomed Y. Effects of hypothermia on brainstem auditory evoked potentials in humans. Ann Neurol. 1987; 22 (4): 507-513.

Melo ES, Barbeiro HV, Ariga S, Goloubkova T, Curi R, Velasco IT, Vasconcelos D, Soriano FG. Immune cells and oxidative stress in the endotoxin tolerance mouse model. Braz J Med Biol Res. 2010; 43(1): 57-67.

Miyake RS, Reis AG, Grisi S. Sedação e analgesia em crianças. Rev Ass Med Brasil. 1998; 44 (1): 56-64.

Möller AR, Janetta PJ. Evoked potentials from the inferior colliculus in man. Electroencephalogr Clin Neurophysiol. 1982; 53: 612- 620.

Möller AR, Jannetta P, Bennett M, Möller MB. Intracranially recorder responses from human auditory nerve: new insights into the origin of brainstem response evoked potentials. Electroencephalogr Clin 
Neurophysiol. 1981; 52: 18-27.

Moore JK. The human auditory brainstem: A comparative view. Hear Res. 1987; 29: 1-32.

Musiek FE, Baran JA. The auditory system - anatomy, physiology and clinical correlates. Boston: Pearson; 2007.

Mussi-Pinhata MM; Rego MAC. Particularidades imunológicas do prétermo extremo: um desafio para a prevenção da sepse hospital. $J$ Pedriat. 2005; 81(1): S59-S68.

Nakabayashi M, Kurokawa A, Yamamoto Y. Immediate prediction of recovery of consciousness after cardiac arrest. Intensive Care Med., $2001 ; 27: 1210-14$.

Norrix LW, Irepanier S, Atlas M, Kim D. The auditory brainstem response: latencies obtained in children while under general anesthesia. J Am Acad Audiol. 2012; 23: 57-63.

Novais CM, Pires-Alves M. PCR em tempo real. Rev Biotecnol Ciência e Desenvolvimento. 2004; 33: 10-13.

Opal SM; DePalo VA. Anti-inflamotory cytokines. Chest. 2000; 117 (4): 1162-1172.

O'Sullivan SB, Schmitz TJ. - Fisioterapia, Avaliação e Tratamento. São Paulo: Manole, segunda edição,1993.

Palaskas CW, Wilson MJ, Dobie RA. Electrophysiologic assessment of low-frequency hearing: sedation effects. Otolaryngol Head Neck Surgery. 1989; 101: 434- 441.

Pereira Junior GA, Marson F, Abeid M, Ostini FM, Souza SH, Basile- 
Filho A. Fisiopatologia da sepse e suas implicações terapêuticas. Medicina, Ribeirão Preto. 1998; 31: 349-362.

Pfaffl MW. A new mathematical model for relative quantification in realtime RT-PCR. Nucleic Acids Res. 2001; 29 (9): e45.

Pincze Z, Lakatos P, Rajkai C, Ulbert I, Karmos G. Effect of deviant probability and interstimulus/interdeviant interval on the auditory N1 and mismatch negativity in the cat auditory cortex. Cogn Brain Res. 2002; 13: 249-253.

Rinaldi S, Consales G, Gaudio AR. Changes in auditory evoked potentials induced by postsurgical sepsis. Minerva Anestesiol. 2008; 74: 245-250.

Rosemblum SM, Ruth RA, Gal TJ. Brainstem auditory evoked potential monitoring during profound hypothermia and circulatory arrest. Annals of otology, rhinology, and laryngology. 1985; 94: 281-283.

Russel JA. Management of sepsis. N Engl J Med. 2006; 355:16991713.

Ryan A. Hearing sensitivity of the Mongolian gerbil, Meriones Unguiculates. J Acoust Soc Am.1976; 59 (5): 1222-1226.

Sales Junior JAL, David CM, Hatum R, Souza PCSP, Japiassú A, Pinheiro CTS, Friedman G, Silva OB, Dias MD, Koterba E, Dias FS, Piras C, Luiz RR e grupo de estudo de sepse do fundo AMIB. Sepse Brasil: estudo epidemiológico da sepse em Unidades de Terapia Intensiva brasileiras. Rev. bras. ter. intensiva. 2006; 18(1): 9-17.

Seelig VC. Questões atuais relacionadas ao uso de modelos animais em pesquisa científica. [monografia]. Porto Alegre: Universidade Federal do rio Grande do Sul; 2007. 
Sharshar T, Annane D, Lourin de La Grandmaison G, Brouland JP, Hopkinson NS, Gray F. The neuropathology of septic shock. Brain Pathol. 2004; 14: 21-33.

Sharshar T, Hopkinson NS, Orlikowski D, Annane D. The brain in sepsis - culprit and victim. Crit Care. 2005; 9: 37- 44.

Silva FP. Disfunções Neurológicas. In: Silva FP; Velasco IT. Sepse. Barueri: Manole. 2007, págs. 108-113.

Silva FP. Nomenclatura e Epidemiologia. In: Silva FP; Velasco IT. Sepse. Barueri: Manole. 2007, págs. 12-18.

Sims MH, Horohov JE. Effects of xylazine and ketamine on the acoustic reflex and brain stem auditory-evoked response in the cat. $A m$ $J$ Vet Res. 1986; 47(1): 102-109.

Smith $\mathrm{DI}$, Mills $\mathrm{JH}$. Anesthesia effects: auditory brain-stem response. Electroencephalogr Clin Neurophysiol. 1989; 72(5): 422-428.

Smith DI, Kraus N. Postnatal development of the auditory brainstem response (ABR) in the unanesthetized gerbil. Hear Res. 1987; 27: 157164.

Sohmer H, Gafni M, Havatselet G. Persistence of auditory nerve response and absence of brain-stem response in severe cerebral ischaemia. Electroencephalogr Clin Neurophysiol. 1984; 58(1): 65-72.

Soriano FG, Silva FP. Nomenclatura e Epidemiologia. In: Silva FP, Velasco IT. Sepse. São Paulo: Manole. 2007, pags. 12-18.

Sousa LCA, Piza MRT, Costa SS. Brainstem evoked auditory potential (ABR) in neurology and neurosurgery. Otolaryngol Head Neck Surg. 
1995.

Sousa LCA, Piza MRT, Rodrigues LS, Ruiz DB, Schmidt VB. O BERA como instrumento de avaliação funcional do tronco cerebral em cirurgias com hipotermia profunda e parada circulatória total. Rev Bras Otorrinolaringol. 2003; 69 (5): 664-670.

Spoendlin $\mathrm{H}$. Innervation densities of the cochlea. Acta Otoryngologica. 1972; 73: 235-248.

Stehno-Bittel, L. Neuroplasticidade. In: Lundy-Ekman L. Neurociência: Fundamentos para reabilitação. Rio de Janeiro: Elsevier; 2008, págs. 61-70.

Stockard JJ, Sharbrough FW, Tinker JA. Effects of hypothermia on the human brainstem auditory response. Ann Neurol. 1978; 3 (4): 368-370.

Sutton LM, Frewen T, Marsh R, Jaggi J, Bruce DA. The effects of deep barbituric coma on multimodality evoked potentials. J Neurosurg. 1982; 57: 178-185.

Tak PP; Firestein GS. NF-kB: a key role in inflammatory diseases. $J$ Clin Invest . 2001; 107 (1): 7-11.

Toyoda T, Tsukamoto T, Takasu S, Shi L, Hirano N, Ban H, Kumagai $\mathrm{T}$, Tatematsu M. Anti-inflammatory effects of caffeic acid phenethyl ester (CAPE), a nuclear factor-kB inhibitor, on Helicobacter pyloriinduced gastritis in Mongolian gerbils. International Journal of Cancer. 2009; 125 (8): 1786-1795.

Van Looij MA, Liem SS, Van der Burg H, Van der Wees J, De Zeeuw $\mathrm{Cl}$, Van Zanten BG. Impact of conventional anesthesia on auditory brainstem responses in mice. Hear Res. 2004; 193 (1-2): 75-82. 
Welkoborsky HJ, Lowitzsch K. Auditory brain stem responses in patients with human immunotropic virus infection of different stages. Ear Hear. 1992; 13(1): 55.57.

White BC; Sullivan JM; DeGracia DJ; O'Neil BJ; Neumar RW; Grossman LI; Rafols JA; Krause GS. Brain ischemia and reperfusion: molecular mechanisms of neuronal injury. J Neurol Sci. 2000; 179: 133.

Young GB, Bolton CF, Austin TW, Archibald YM, Gonder J, Wells GA. The encephalopathy associated with septic illness. Clin Invest Med. 1990; 13: 297-304.

Zauner C, Gendo A, Kramer L, Funk GC, Bauer E, Schenk P, Ratheiser K, Madl C. Impaired subcortical and cortical sensory evoked potential pathways in septic patients. Crit Care Med. 2002; 30(5): 11361192.

Zipfel GJ, Lee JM, Choi DW. Reducing calcium overload in the ischemic brain. New England Journal of Medicine. 1999; 341: 15431544. 